\title{
LA HACIENDA Y FORTUNA DE DON RUY LÓPEZ Dávalos, Condestable de Castilla
}

\author{
María Antonia Carmona Ruiz ${ }^{1}$ \\ Universidad de Sevilla
}

Recibido: 23 de noviembre de 2020

Aceptado: 25 de abril de 2021

\begin{abstract}
Resumen:
A través de este trabajo pretendemos analizar la formación y evolución de la hacienda de Ruy López Dávalos, a partir de su llegada a la corte castellana durante el reinado de Juan I, viéndose especialmente favorecido por Enrique III con importantes cargos, un extenso señorío y otros bienes económicos que utilizó para ampliar su patrimonio. Su caída en desgracia durante la minoría de edad de Juan II supuso la confiscación de sus bienes que se repartieron entre importantes miembros de la casa del rey. Sus hijos intentaron sin éxito recuperar ese capital, realizando incluso su hipotético reparto.
\end{abstract}

\section{Palabras clave}

Ruy López Dávalos, reino de Castilla, condestable, patrimonio, señorío.

\begin{abstract}
This article aims to analyse the formation and evolution of Ruy López Dávalos' estate, from his arrival at the Castilian court during the reign of Juan I, being especially favoured by Enrique III with important posts, an extensive lordship and other economic assets that he used to expand his patrimony. His fall from grace during the minority of John II meant that his assets were confiscated and distributed among important members of the king's household. His sons tried unsuccessfully to recover this capital, even making their hypothetical distribution.
\end{abstract}

\section{Keywords}

Ruy Lopez Davalos, kingdom of Castile, constable, patrimony, lordship.

\section{Riassunto}

Attraverso questo lavoro intendiamo analizzare la formazione e l'evoluzione della tenuta di Ruy López Dávalos, dal suo arrivo alla corte castigliana durante il regno di Giovanni I, essendo particolarmente favorito da Enrico III con posizioni importanti, una vasta signoria e altri beni economici che ha utilizzato per espandere il suo patrimonio. La sua caduta in disgrazia durante la minorità di Giovanni II significò la confisca dei suoi beni che furono distribuiti tra i membri importanti della casa del re. I suoi figli hanno cercato senza successo di recuperare questo capitale, anche facendo la loro ipotetica distribuzione.

\section{Parole chiave}

Ruy López Dávalos, Regno di Castiglia, Conestabile, Tenuta, Domaine.

\footnotetext{
1 Departamento de Historia Medieval y Ciencias y Técnicas Historiográficas. Facultad de Geografía e Historia Universidad de Sevilla. C/ María de Padilla s/n. Correo electrónico: mantonia@us.es. Orcid: https://orcid.org/0000-0003-1085-693X.
} 


\section{Introducción ${ }^{2}$}

Durante la segunda mitad del siglo XIV se experimentó en el Occidente medieval un importante cambio en la configuración de las élites de poder, fenómeno del que no fueron ajenas las monarquías hispánicas, donde desapareció una gran parte de los grandes linajes que tradicionalmente controlaron el gobierno, llegando otros más modestos que irían acaparando cargos y poder. Los factores que pueden explicar la consolidación de la que algunos denominan "nueva nobleza", son muy variados y, de hecho, numerosos estudios sobre la nobleza castellana bajomedieval realizados en los últimos años, hacen bastante hincapié en estas cuestiones. No podemos detenernos aquí a analizarlas, pero sí podemos destacar algunos comunes a Europa medieval: crisis dinásticas y conflictos sucesorios que algunos aprovecharon para su ascenso y ampliación de poder económico, pero también el interés de los monarcas por aumentar su autoridad frente a la nobleza tradicional y sus parientes. Esta realidad estaba muy presente en Castilla, con la dinastía Trastámara y su necesidad de respaldo, lo que puede explicar el ascenso y encumbramiento de algunos linajes o personas a través de unas etapas, que definió hace ya algunos años Emilio Mitre, y que suponía para algunos personajes el paso de la hidalguía a la nobleza señorial ${ }^{3}$. Es un fenómeno que era perceptible con los dos primeros Trastámara, pero que se manifestó claramente con la llegada al poder de Enrique III, al formarse un consejo privado en el que, entre otros, participó Ruy López Dávalos.

El caso particular del que llegó a convertirse en condestable de Castilla, es uno de esos ejemplos de progreso político y promoción social, aunque, a diferencia de otros, su ascenso se vio truncado por unas luchas por el poder que en otro momento le favorecieron. A grandes rasgos, podemos considerar que fue la minoría de Enrique III la que le permitió alcanzar el poder y fue la minoría de Juan II la que lo apartó de él. Su abrupta caída y la confiscación de todos sus bienes y cargos, dificulta bastante la labor de análisis de su patrimonio.

La vida de Ruy López Dávalos ha sido objeto de estudio de numerosos investigadores. Entre ellos, podemos destacar el trabajo de Francisco Ruano y Prieto que con un espíritu encomiástico elaboró una biografía del condestable ${ }^{4}$. Asimismo, Emilio Mitre, en su estudio sobre la evolución de la nobleza durante el reinado de Enrique III, hace referencia específica a nuestro personaje ${ }^{5}$, al igual que Torres Fontes en su artículo

\footnotetext{
2 Este trabajo se ha realizado dentro del Proyecto de Investigación "La construcción de una cultura fiscal en Castilla: poderes, negociación y articulación social (ca. 1250-1550). PGC2018-097738-B-100. Abreviaturas utilizadas: $\mathrm{ACS}=$ Archivo Catedral de Sevilla; ADM= Archivo Ducal de Medinaceli; $\mathrm{AGA}=$ Archivo General de Andalucía; AGN= Archivo General de Navarra; AGS= Archivo General de Simancas; $\mathrm{AHNOB}=$ Archivo Histórico de la Nobleza; $\mathrm{AHPZ}=$ Archivo Histórico Provincial de Zaragoza; AIVDJ= Archivo del Instituto Valencia de don Juan; AMM= Archivo Municipal de Murcia; AMS= Archivo Municipal de Sevilla; BNE= Biblioteca Nacional de España; RAH= Real Academia de la Historia; $\mathrm{CODOIN=}$ Colección de documentos inéditos para la Historia de España.

Mitre Fernández, Evolución de la nobleza, pp. 37-38.

4 Ruano Prieto, "El condestable".

5 Mitre Fernández, Evolución de la nobleza. Además de numerosas referencias a lo largo del libro, le dedica específicamente las páginas 156 a 158.
} 
sobre los condestables de Castilla, deteniéndose especialmente en el momento de su declive ${ }^{6}$. Por otro lado, Yolanda Guerrero Navarrete realizó una breve semblanza de este personaje en la introducción al libro en el que publicó el documento del proceso contra el condestable, incluyendo una breve aproximación a su patrimonio ${ }^{7}$. Más completo es el ensayo en el que Luis Suárez Fernández analizó la vida del condestable ${ }^{8}$. Óscar Perea realizó también una breve semblanza en un trabajo en que utiliza el Cancionero de Baena como fuente principal para su estudio9. Además, Santiago González Sánchez lo ha examinado en sus trabajos centrados en el análisis de la nobleza castellana durante la minoría de Juan $\mathrm{II}^{10}$. Sin embargo, todos estos estudios se centran principalmente en su actividad política, mientras que de su poder económico tan sólo realizan una breve aproximación que en todos los casos es mucho más incompleta que la que aquí presentamos. Teniendo en cuenta esto, la intención principal de este trabajo es realizar un examen más profundo y sistematizado de la hacienda del condestable, aún a sabiendas de la dificultad que tenemos para ello, a consecuencia de la falta de fuentes documentales.

\section{El ascenso político de Ruy López Dávalos y sus consecuencias económicas}

En el ya clásico estudio que el profesor Emilio Mitre realizó sobre la evolución de la nobleza castellana durante el reinado de Enrique III, estableció cuatro etapas que la nueva nobleza experimentó en su programa de ascenso al poder (cargo en la Corte; concesión real de señorío o rentas; compra y permuta de señoríos; y creación de mayorazgo) ${ }^{11}$. Este proceso se observa claramente en Ruy López Dávalos, quien entró en la corte al final del reinado de Juan I, convirtiéndose en su camarero. A partir de ahí, más que en etapas sucesivas, podemos considerar que el resto de los beneficios los consiguió en un proceso simultáneo, en el que paralelamente a la adquisición de nuevos cargos, fue acumulando señoríos y rentas, bien mediante concesión real, bien mediante compra o permuta, utilizando para ello los beneficios que sus diferentes oficios le fueron aportando. De hecho, como privado del rey, para lograr controlar en su nombre los engranajes políticos del reino, además de conseguir unas fuertes relaciones clientelares, debía de apoyarse en un consistente patrimonio personal ${ }^{12}$. Por ello, antes de acercarnos al estudio de su hacienda, es conveniente hacer un análisis de los cargos que consiguió, ya que estos les permitieron obtener rentas, salarios e influencia suficiente como para amasar una notable fortuna.

\footnotetext{
6 Torres Fontes, "Los condestables" pp. 68-77.

7 Guerrero Navarrete, Proceso y sentencia, pp. 15 y 17, hace una breve relación de sus oficios, títulos y señoríos.

8 SuÁrez Fernández, "Auge y caída".

9 Perea Rodríguez, "El Cancionero de Baena".

10 Así, además de numerosas referencias a su actividad política, analiza también parte de su patrimonio en su tesis doctoral. GonzÁlez SÁnchez, La Corona de Castilla: Vida política. Buena parte de la información la repite en el libro La alta nobleza castellana, pp. 221-233.

11 Mitre Fernández, Evolución de la nobleza, pp. 37-38.

12 Foronda, "La privanza dans la Castille", p. 153.
} 
Procedente de una familia de fronteros asentada en Úbeda, su ascenso se inició durante el reinado de Juan I, cuando entró al servicio de la Corona, posiblemente después de haberse significado en la guerra con Portugal. En la Corte debió adquirir la suficiente confianza del rey y del arzobispo Pedro Tenorio para que este último le entregara la custodia de las arcas personales del monarca tras su fallecimiento. A esta circunstancia hace referencia el propio arzobispo en una carta que envió al concejo de Sevilla en la que denominaba a Ruy López Dávalos "criado" del rey ${ }^{13}$. Realmente, ejerció como camarero del rey, lo que recogen tanto la Crónica de Pedro López de Ayala como la Crónica Anónima de Enrique III. No obstante, este es un término bastante ambiguo, ya que con él se hacía referencia a diferentes oficiales de la casa del rey, de los que el más importante era el camarero mayor, cargo que durante el reinado de Juan I ejerció Juan Fernández de Velasco. Teniendo en cuenta esto, y presuponiendo que fue camarero mayor de Enrique III, Suárez Fernández planteó la hipótesis de que sirviera en la casa de éste cuando era príncipe, posiblemente como su camarero, y que hubiera continuado en el cargo tras su acceso a la Corona ${ }^{14}$. Sin embargo, la Crónica anónima de Enrique III es bastante clara al respecto, ya que en ella se indica que era camarero de Juan I:

Se salieron de la dicha camara, aviendola primero todas zerrado y entregado las llaves al dicho Rrui Lopez dAualos, camarero del rrey don Juan, que antes las thenia para que las guardase como las avia guardado ${ }^{15}$.

Así pues, estaba vinculado directamente a la Casa del rey, y no a la del príncipe, y en ella continuó tras la llegada al trono de Enrique III. Además, hay que decir que, durante el reinado de Enrique III, Juan Fernández de Velasco siguió como camarero mayor del rey y a éste le sucedió en 1418 su hijo Pedro ${ }^{16}$. Por lo tanto, Ruy López Dávalos nunca fue camarero mayor del rey. De hecho, el oficio que realmente ostentó fue el de camarero mayor de la cámara de los paños ${ }^{17}$, cargo de reciente creación y más cercano al monarca que el camarero mayor, ya que su función no se limitaba a cuidar de las vestiduras reales, sino que podía encargarse de cualquier otra tarea que le encargara el rey $^{18}$. Lo mantuvo hasta que en 1423 fue sustituido por don Álvaro de Luna, aunque no siempre lo ejerció directamente, y de hecho al menos en 1420 quien lo desempeñaba en su nombre era Sancho de Hervás ${ }^{19}$.

\footnotetext{
3 1391, mayo, 13, Illescas. ACS, secc. IX, leg. 133, n 7. Edit. Montes Romero-Camacho "La polémica del testamento", pp. 468-472.

14 SuÁrez Fernández, “Auge y caída” p. 50.

5 Crónica anónima de Enrique III, p. 47.

16 Salazar y Acha. La casa del rey, p. 250.

17 Salazar y Acha. La casa del rey, pp. 256-257. Ximena Jurado, Historia, o Anales, p. 403. Este último indica que en 1420 ejercía el cargo Sancho de Ervás, como delegado del condestable.

18 Salazar y Acha. La casa del rey, pp. 256-257. Cañas Gálvez, “La Casa de Juan I”, pp. 149-152.

19 Galíndez de Carvajal, Crónica de Juan II, p. 381.
} 
La cercanía al monarca que el oficio le dio y la confianza que de él se ganó, puede explicar cierta influencia en la Corte de Juan I, que Juan Dávalos ejemplifica con el compromiso que, junto con otros privados, contrajo con el rey de sufragar parte de la construcción del monasterio del Paular ${ }^{20}$. Otra muestra de esa ascendencia está en que tras la muerte de este monarca se convirtió en el depositario de su documentación privada $^{21}$, lo que explica su presencia en Madrid durante la celebración de las Cortes de 1391. Allí, además, por su cargo actuó junto con Juan Fernández de Velasco como anfitrión de la embajada francesa que fue a entrevistarse con Enrique III $^{22}$. Asimismo, tuvo desde siempre bastante cercanía al futuro Enrique III, como éste indica al agradecer los "buenos e leales servicios que vos ... avedes fecho a mi en criança" 23 .

La caótica situación que se vivió durante la minoría de edad del nuevo rey permitió que algunos miembros de la pequeña nobleza se vieran beneficiados políticamente, entre los que destacaron Juan Hurtado de Mendoza y Diego López de Zúñiga, que fueron quienes realmente controlaron el Consejo, y a los que se fue acercando Ruy López Dávalos. Muestra de su ascendencia es el hecho de que estos tres personajes fueron los principales beneficiarios de la confiscación de los bienes de las juderías castellanas tras el ataque de $1391^{24}$.

Declarada la mayoría de edad de Enrique III en agosto 1393, se inició el gobierno personal del monarca, pasando a formar parte de su consejo privado, encargándose principalmente de las actividades de carácter militar. Por ello participó en las operaciones de liquidación de los parientes de Enrique III: don Fadrique, duque de Benavente, don Alfonso, conde de Noreña y Gijón y especialmente contra doña Leonor de Navarra ${ }^{25}$. De hecho, su intervención en el acuerdo entre el conde de Noreña y Enrique III de 1394, le permitió el control de la merindad de Asturias y las fortalezas que el rey había arrebatado a don Alfonso ${ }^{26}$.

A la par que contribuía al fortalecimiento del poder político del monarca, comenzó a obtener algunas rentas y territorios y también a ejercer nuevos oficios. Así, compatibilizando la función cortesana de camarero, que mantuvo hasta su caída, obtuvo diversos cargos institucionales. No obstante, debido a su diversidad de obligaciones, no siempre

\footnotetext{
20 Dávalos y Ayala, Vida, hechos ilustres, fol. 66v. El resto de los que se comprometieron a sufragar la construcción del monasterio fueron el conde de Trastámara, Pedro Enríquez, Diego Hurtado de Mendoza, almirante de Castilla, Juan Hurtado de Mendoza y Diego López de Zúñiga.

21 López de Ayala, Crónica de Juan I, p. 164. Crónica anónima de Enrique III, p. 47.

22 Crónica anónima de Enrique III, p. 89.

23 1394, diciembre, 7. Valladolid. Enrique III dona a Ruy López Dávalos la villa de Arjona. AGS. Mercedes y Privilegios, leg. 9, fol. 35. Edit. Mitre Fernández, La extensión del régimen, pp. 75-79.

24 Vid. Montes Romero-Camacho, "Antisemitismo sevillano", Mitre Fernández, Los judíos de Castilla.

25 Así, presenció en Burgos el apresamiento de don Fadrique, en Sepúlveda organizó la captura de doña Leonor para ser conducida a Navarra junto a su marido el rey Carlos III, según el pacto que éste había establecido con Ruy López Dávalos, y acompañó al rey a Gijón cuando se estableció el acuerdo con el conde don Alfonso. SuÁrez Fernández, "Auge y caída”, p. 53.

26 "Otrosi, la merindad de Asturias e las fortalezas que el rey avía cobrado del conde, que fincasen en manos de Rui López de Abalos, e esto por consentimiento del conde". LóPez de Ayala, Crónica de Enrique III, p. 232.
} 
los ejerció directamente, sino que lo hicieron lugartenientes de su confianza. Eran oficios muy relacionados con la capacidad militar que había demostrado desde el principio y también con su ascendencia sobre el rey, por lo que intervino como representante del poder real en diferentes concejos castellanos con el fin de restaurar la autoridad monárquica en momentos en que diferentes conflictos internos habían desestabilizado su situación política.

Tan pronto como Enrique III asumió el poder, este inició un programa político encaminado a reforzar la autoridad real, bastante mermada a consecuencia del periodo de anarquía política que Castilla padeció durante su minoría de edad. Además de someter a sus parientes, continuó con el programa de centralización iniciado por su padre. Por ello, con el pretexto de pacificar algunas ciudades, el monarca realizó una intervención directa en algunos concejos mediante el envío de fieles colaboradores como corregidores, entre los que designó a Ruy López Dávalos, que se mostró especialmente efectivo. Esta institución no era nueva, ya que existía desde el gobierno de Alfonso XI, pero fue durante su reinado cuando se empezó a implantar el corregimiento en un reducido número de núcleos. El desempeño de este oficio llevaba consigo adscrito importantes funciones de carácter administrativo, judicial, político y militar, por lo que el corregidor se convirtió en el representante por antonomasia de la autoridad y del poder real en la esfera local y por ello eran personas cercanas al monarca y cuidadosamente elegidas ${ }^{27}$. Hay que destacar que fue corregidor de algunos concejos en momentos especialmente complicados, en los que los enfrentamientos internos por el control de su gobierno desembocaron en muchas ocasiones en tumultos. En estos casos su actuación fue rápida y en algunas ocasiones se caracterizó por una mezcla de diálogo con métodos expeditivos. Aunque continuó manteniendo esos corregimientos durante un dilatado espacio de tiempo, la realidad es que, tras una rápida y efectiva intervención, delegó su función en tenientes de corregidor que fueron los que mantuvieron posteriormente controlado el gobierno de las ciudades. En este sentido, debemos destacar su vinculación directa con algunos de los territorios donde ejerció este cargo, caso del obispado de Jaén, o el de Ávila, en donde tenía concentrados buena parte de sus señoríos.

Así, fue corregidor de Baeza al menos entre 1394 y $1401^{28}$, interviniendo en algunas de las reyertas urbanas que se estaban produciendo desde la época de la minoría del rey. Tras la pacificación de la ciudad delegó en dos Mendozas emparentados con él. En primer lugar, en Alfonso Fernández de Mendoza, escribano del rey ${ }^{29}$, y posteriormente, al menos entre 1399 y 1401, en Luis López de Mendoza ${ }^{30}$, primo de López Dávalos,

27 Mitre Fernández “Mecanismos institucionales", p. 318. Vid. también Mitre Fernández, La extensión del régimen.

28 Así lo señala Ximena Jurado, basándose en la consulta de los libros de cabildo de Baeza, e indicando que en ellos aparece su nombre como tal. Ximena Jurado, Historia o anales, pp. 381 y 386.

29 Ximena Jurado. Historia o anales, p. 381; Dávalos y Ayala, Vida, hechos ilustres, fol. 69r-v.

30 Argote de Molina transcribe un padrón de hidalgos de Baeza de 1401, en que figura como corregidor Ruy López Dávalos y su teniente Luis López de Mendoza. Argote de Molina, Nobleza de Andalucía, p. 568. A ese padrón hace también referencia Ximena Jurado. Ximena Jurado. Historia o anales, p. 386. L. Salazar y Castro, por otro lado, en una breve nota indica que Luis López de Mendoza en 1399 era 
con quien tenía una estrecha relación y que fue además comendador de Bedmar, de la orden de Santiago y regidor de Jaén ${ }^{31}$.

En el caso de Úbeda, aunque obtuvo el cargo ya muy tardíamente, había estado interviniendo en fechas anteriores, tanto en el nombramiento de corregidores cercanos a él, como eran su sobrino Ruy López de Mendoza y su primo Luis López de Mendoza ${ }^{32}$, como en los intentos de solución de los conflictos que el enfrentamiento de los Trapera y los Aranda habían causado en la ciudad ${ }^{33}$. Finalmente, en octubre de 1419 fue nombrado corregidor de la ciudad de Úbeda, esta vez en medio del conflicto provocado por la designación como alcaide de Quesada de Gonzalo de Morales. En esta ocasión no actuó directamente en el problema, ya que fue Juan Fernández de Pedrosa, su teniente de corregidor el que procedió en su lugar ${ }^{34}$.

Respecto a Ávila, al parecer fue el primer corregidor que tuvo la ciudad en 1396, ejerciendo como su teniente de corregidor Juan Fernández Orejón ${ }^{35}$. Siguió desempeñando el cargo en años posteriores de manera nominal, ya que en 1408 lo profesaba en su lugar Álvar Rodríguez de Ciudad Rodrigo ${ }^{36}$. Además, hacia 1415 obtuvo el cargo de merino de Carrión y su tierra, ya que lo ejercía en ese año ${ }^{37}$.

Más importante fue el cargo de adelantado de Murcia, que obtuvo en octubre de $1396^{38}$, después de su intervención directa en el enfrentamiento entre Manueles y Fajardos por el dominio de la ciudad de Murcia. Tampoco ejerció directamente el oficio, siendo su hermano, Lope Pérez Dávalos, como su lugarteniente ${ }^{39}$, el que en realidad gobernó. Éste no consiguió el control completo de la ciudad, por lo que Ruy López Dávalos intervino expeditivamente en 1399, restableciendo el poder real y el control del concejo murciano. Su hermano continuó ejerciendo como teniente de adelantado hasta su muerte en 1405, sustituyéndolo Garcí Fernández de Oter de Lobos entre 1405 y 1417,

corregidor de Baeza, sin especificar la fuente de información. RAH, Col. Salazar y Castro, M-1, fo 235. Este dato, posiblemente mal recogido, ha llevado a Mitre Fernández, a Chamocho Cantudo y a Porras Arboledas a considerar que Luis López de Mendoza fue corregidor de la ciudad en 1399, algo que no concuerda con la información de Argote de Molina y Ximena Jurado. Mitre Fernández, La extensión del régimen, p. 30. Сhamocho Cantudo, Justicia real, pp. 217-218. Porras Arboledas, "La aristocracia urbana", p. 275.

31 Porras Arboledas, "La aristocracia urbana", pp. 274-276.

32 En torno a 1396, fue nombrado corregidor de la ciudad Ruy López de Mendoza, sobrino del condestable, hacia 1400 era Luis López de Mendoza quien ejercía como corregidor en Úbeda. Mitre FernÁndez, Evolución de la nobleza, p. 158

33 Argote de Molina, Nobleza de Andalucía, pp. 570-571.

34 Ximena Jurado, Historia o anales, p. 402.

35 González Dávila, Historia de la vida, p. 124.

36 Luis López y Ser Quijano, Documentación medieval, no 59, pp. 133-134.

37 González SÁnchez, La Corona de Castilla, p. 2032.

38 Su nombramiento se produjo el 5 de octubre de 1396. Pérez, El gobierno y la administración, p. 422.

El 16 de octubre ya había tomado posesión de su cargo, según se puede ver en el documento de exención de moneda forera de Murcia.

39 1397, abril 15. Tordesillas. Carta de Enrique III a las autoridades de Murcia y Cartagena ordenando, a petición de Ruy López Dávalos, que consientan actuar a su hermano Lope Pérez Dávalos como su lugarteniente en el adelantamiento de Murcia. RAH, Col. Salazar y Castro, D.11, f. 263v. 
para posteriormente ejercer como teniente de adelantado su hijo Pedro López Dávalos, manteniéndose en el cargo hasta 1423 en que su padre fue destituido ${ }^{40}$. Las cantidades que don Ruy percibió del concejo de Murcia como adelantado mayor fueron bastante cuantiosas, y así, en 1399 se le pagaron 10.500 maravedíes que se recaudaron entre el vecindario a través de préstamos populares ${ }^{41}$.

Asimismo, Ruy López Dávalos también ejerció como corregidor de Murcia en 1418, con Alfonso Fernández Frías como teniente de corregidor ${ }^{42}$, en un momento complicado, ya que acababa de fallecer la reina Catalina de Lancaster, con un salario asignado de 220 maravedíes diarios que cobró entre septiembre y diciembre de dicho año. Al regresar a la corte al final de ese año pidió que se le remunerase con 5.000 maravedíes de dos blancas anuales por defender los problemas de la ciudad, a lo que el concejo murciano se negó, comprometiéndose únicamente a pagarle dos florines diarios cuando circunstancialmente estuviera gestionando asuntos relacionados con esta ciudad ${ }^{43}$. Por otro lado, también en el reino de Murcia, ostentó el cargo de alcalde entre cristianos y moros del obispado de Cartagena, por el que sabemos que recibía del rey 4.000 maravedíes anuales ${ }^{44}$.

En esta fulgurante carrera consiguió finalmente alcanzar la dignidad de condestable, un cargo de carácter militar que suponía tener el mando supremo sobre los ejércitos después del rey, beneficiado además con una notable remuneración ${ }^{45}$. Sus principales atribuciones eran: autoridad suprema en el ejército, sin que pudiera hacerse nada sin su licencia; jurisdicción civil y criminal; facultad para nombrar oficiales y designar justicias; vengar injurias hechas a los caballeros de su hueste; e inspeccionar y exigir el reparo de castillos y fortalezas fronterizas ${ }^{46}$.

Era la primera vez que ostentaba este cargo alguien que no tenía sangre real, como bien se dedica a recalcar Juan Dávalos ${ }^{47}$. Juan I creó esta dignidad en 1382 a imitación de Francia para el infante Alfonso de Aragón, conde de Denia y Ribagorza y marqués de Villena, como recompensa por su ayuda a la causa trastamarista ${ }^{48}$. Sin embargo, en 1391 se le despojó del cargo, que fue entregado a don Pedro Enríquez, conde de Trastámara ${ }^{49}$, aunque por poco tiempo, ya que cuando Enrique III alcanzó la mayoría de edad, este perdió sus rentas y tuvo que abandonar la Corte en 1393, refugiándose en

\footnotetext{
40 Ruano Prieto, "El condestable", VIII, p. 180.

41 Martínez Carrillo, Revolución urbana, pp. 352-353.

42 1418, julio 2. Tordesillas. Edit. Bermúdez Aznar, El corregidor, doc. 16, pp. 282-285, que también publica la subrogación, realizada en 1418, agosto, 5. Tordesillas, doc. 15, pp. 280-282.

43 Martínez Carrillo, Revolución urbana, p. 355.

44 AHNOB, Osuna C. 286, D. 27. AMM, Cartulario Real 1391-1412, fols. 16r-17v. Publica Torres Fontes "El alcalde entre moros", pp. 78-79.

45 Dávalos y Ayala, Vida, hechos ilustres, hace un interesante estudio de esta dignidad en el capítulo 14, fols. 87r-91r. La analizó TorRes Fontes "Los Condestables".

46 Torres Fontes "Los Condestables" p. 65.

47 Dávalos y Ayala, Vida, hechos ilustres, fol. 87r.

48 1382, Julio, 6, Ciudad Rodrigo. Publica López de Ayala Crónica de Juan I, pp. 147-148.

49 LóPez de Ayala, Crónica de Enrique III, pp. 177-178.
} 
Galicia hasta su muerte, acaecida en mayo de 1400. Es muy probable que también se le quitara este cargo, y que después de que el infante Alfonso de Aragón lo reclamara y no llegara a ejercerlo al regresar a Aragón, quedara vacante. Por último, en 1399 Ruy López Dávalos fue nombrado condestable de Castilla. No contamos con el documento de su designación, pero en octubre de 1399 empezó a firmar como tal ${ }^{50}$. Era ya un hombre maduro que pasaba la cuarentena, y puede decirse que con este nombramiento culminaba su ascenso, reconociéndosele un trabajo que llevaba haciendo desde hacía algún tiempo, destacando especialmente su protagonismo en la guerra contra Portugal. Como ya se ha indicado, era la primera vez que desempeñaba este cargo alguien ajeno a la familia real, y también era la primera vez que se cumplía con las obligaciones que conllevaba. Tanto Alfonso de Aragón como Pedro Enríquez se habían limitado a cobrar la importante retribución que suponía, por lo que Ruy López Dávalos fue el primer condestable que desempeñó sus funciones.

Así pues, considerando que retuvo buena parte de los oficios que consiguió a lo largo de su carrera, aunque no siempre los ejerció directamente, debió de obtener de ellos unos ingresos bastante elevados. A esto hay que añadirle también las cantidades de dinero que anualmente le entregaba el rey "para su mantenimiento", por su lealtad y servicios. Desconocemos la cuantía exacta que tenía asignada, pero tenemos datos para suponer que eran unas sumas notables. Así, sabemos que en 1403 el alcabalero real Pedro Ortiz, le pagó por orden de Enrique III, 300.000 maravedíes, "para ayuda de su costa e con que pudiese sostener la gente que tenía", y en 1408, 40.000 maravedíes a cuenta de los 100.000 que, con cargo a las alcabalas de Sevilla, Juan II le mandó librar para su mantenimiento, "los quales, el dicho señor Rey, mi padre, le mandaua dar cada año para su mantenimiento por sus alualaes" ${ }^{\prime 1}$. Esa cantidad se debió de aumentar, ya que cuando en 1423 se embargó su capital, el rey le proporcionaba cada año 200.000 maravedíes Además, a través de ese mismo documento, sabemos que Juan II le había concedido 60.000 maravedíes en tierra anuales para el mantenimiento de 40 lanzas $^{52}$.

Además, como miembro de la corte, debía de ser también objeto de numerosas dádivas puntuales, que se pueden ejemplificar en los 60 florines que recibió del rey para jugar en la Nochebuena de $1398^{53}$.

\footnotetext{
50 En un documento del 25 de septiembre de 1399 aparece como camarero y adelantado de Murcia, (CASCales, Discursos históricos, fol. 170-171) mientras que en otro del 18 de octubre del mismo año ya figura como condestable. AGN, Comptos, caja 77, $\mathrm{n}^{\circ}$ 55, IX. CAstro, Catálogo de Comptos, 23, doc. 517, p. 227. Suárez Fernández, "Auge y caída", p. 63. Mitre Fernández, Evolución de la nobleza, p. 63. Juan Dávalos, sin embargo, comenta que algunos historiadores decían que ya era condestable en 1397, idea que no compartía, pensando que el cargo lo recibió en 1400 tras la muerte del conde de Trastámara. Dávalos y Ayala, Vida, hechos ilustres, fol. 85v.

51 Vilaplana Montes, "Un ajuste de cuentas", pp. 432 y 450. Montes Romero-Camacho, "El converso sevillano", p. 370.

52 1423, septiembre, 6. AHNOB, Osuna, C. 286, D. 27.

53 Nogales Rincón, “Un año en la corte”, p. 106.
} 


\section{Cuadro 1.}

\section{Cargos y oficios}

\begin{tabular}{|l|l|}
\hline Cargos & Fecha \\
\hline - Camarero mayor de la cámara de los paños & $1387 ?-1423$ \\
\hline - Condestable de Castilla & $1399-1423$ \\
\hline - Adelantado mayor del reino de Murcia & $1396-1423$ \\
\hline - Alcalde entre moros y cristianos de Cartagena & $1396 ?-1423$ \\
\hline - Merino de Asturias & 1394 \\
\hline - Merino de Carrión y su tierra & 1415 \\
\hline - Corregidor de Ávila & $1396-1408$ \\
\hline - Corregidor de Baeza & $1394-1401$ \\
\hline - Corregidor de Murcia & 1418 \\
\hline - Corregidor de Úbeda & 1419 \\
\hline
\end{tabular}

\section{El patrimonio de Ruy López Dávalos}

El notable poder político que consiguió a lo largo de los años que estuvo al servicio de la Corona, le permitió amasar una sustancial fortuna y acumular un extenso patrimonio señorial, que en buena parte reunió en los primeros años de su privanza con el rey Enrique III, tanto a través de donaciones como mediante compras. Junto a ello, fue acaparando diferentes rentas que consiguió bien por donación real bien por usurpación, obteniendo también importantes beneficios. Desgraciadamente, debido a la falta de documentación solo podemos hacer una aproximación al conocimiento de su holgada hacienda. Así, contamos con muy escasa información directa, por lo que tenemos que completarla a partir de noticias indirectas y muy someras procedentes de las crónicas y de la biografía que realizó Juan Dávalos, de algunos documentos conservados relacionados con el reparto de su patrimonio tras su confiscación en 1423, así como del reparto hipotético de sus bienes que los hijos del condestable realizaron en 1440.

En cualquier caso, y a sabiendas de que tenemos un conocimiento muy parcial de su hacienda, podemos afirmar que, como otros privados del rey, López Dávalos acumuló un patrimonio bastante considerable, que estaba compuesto por propiedades y rentas muy diversas, y diseminadas por todo el reino de Castilla, aunque la mayor parte de estas se concentraba en dos sectores muy concretos: uno en Andalucía, principalmente en la frontera con Granada, y especialmente en el reino de Jaén, mientras que el otro estaba localizado en el obispado de Ávila. Buena parte de estos beneficios patrimoniales los consiguió a través de prerrogativas regias, que le sirvieron para adquirir también otros nuevos, al invertir los beneficios de las donaciones reales en la compra de nuevas rentas y señoríos. 


\subsection{Señoríos}

Ruy López Dávalos consiguió un extenso señorío procedente tanto de donaciones reales como de compras. El grueso más importante lo obtuvo de Enrique III durante sus primeros años de privanza, algo a tener en cuenta ya que frente a los anteriores Trastámara, las concesiones de Enrique III fueron muy pocas y los señoríos que otorgó fueron muy escasos, y precisamente son donaciones vinculadas al apoyo que recibió durante su minoría de edad y en el momento de represión de sus parientes ${ }^{54}$. Así, poco después de octubre de 1393 recibió el señorío de varias villas situadas en la parte meridional del alfoz de Ávila, y en 1394 obtuvo el señorío de Arjona. Paralelamente a estas concesiones, procedió a la compra de otros lugares localizados en su mayor parte cerca de Arjona, aunque también adquirió otros territorios tanto en Andalucía como en otras regiones castellanas.

En diciembre de 1394 recibió de Enrique III la villa Arjona, con todas sus aldeas ${ }^{55}$, es decir, Arjonilla. Juan I concedió este señorío, junto con Écija, a su mujer, la reina Beatriz, aunque ésta nunca llegó a tomar posesión de él, ya que ambas localidades solicitaron continuar siendo realengas, y en esta situación estaban cuando murió el rey ${ }^{56}$. Según se indica en el privilegio de concesión, el monarca únicamente confirmaba la donación que la reina Beatriz había realizado a favor de Ruy López Dávalos de los derechos que podía tener sobre este lugar. En él, además, Enrique III le otorgaba gran amplitud de poderes, en detrimento de la autoridad real, como el nombramiento de corregidores y oficiales de la villa, o la capacidad de convertir en villas a las aldeas y de crear nuevos núcleos de población. Es posible que todo ello tuviera una intención repobladora, ya que era un territorio bastante deshabitado en ese momento. Además, le otorgaba el derecho a construir fortalezas y castillos en su término y de crear una feria o mercado cuando estimara oportuno y la condición de mayorazgo para su primogénito. Asimismo, en un documento aparte, ese mismo día el rey le concedió las tercias ${ }^{57}$, y cuatro años después, el almojarifazgo de esta localidad ${ }^{58}$.

Algunos autores, siguiendo a Ximena Jurado y sin ningún fundamento claro ${ }^{59}$, consideran que López Dávalos tuvo el título de duque de Arjona. No hay datos que confirmen esta suposición, y además hay que tener en cuenta que desde Enrique III, siguiendo el modelo francés, designaba la categoría social del personaje que lo ostentaba (pariente del rey) y no tenía nada que ver con la importancia del señorío ${ }^{60}$. Por otro lado,

\footnotetext{
54 Mitre Fernández, Evolución de la nobleza, p. 110.

55 1394, diciembre 7. Valladolid. AGS. Mercedes y Privilegios, leg. 9, fol 35. Edit. Mitre Fernández. La extensión del régimen, pp. 75-79.

56 López de Ayala. Crónica de Enrique III, p. 194.

57 AGS, Mercedes y privilegios, leg. 9, fol 35. Mitre Fernández, Evolución de la nobleza, p. 115.

58 AGS Mercedes y Privilegios, leg. 1, fol. 487, Mitre Fernández, Evolución de la nobleza, p. 118.

59 Ximena Jurado, Historia, o Anales, 371.

60 Mitre FernÁndez, Evolución de la nobleza, p. 24. Pone como ejemplo el caso del señorío de Benavente que fue un ducado con Fadrique de Trastámara, pero al adquirirlo Juan Alfonso Pimentel tuvo el título de condado.
} 
si hubiera sido así, Juan Dávalos lo hubiera constatado, y sin duda resaltado. Es más plausible que el primer duque de Arjona fuera D. Fadrique de Castro por nombramiento de Juan II cuando en 1423 recibió la villa. De hecho, la Crónica de Alvar García de Santa María indica que recibió el título de duque a raíz de la recepción de la villa de Arjona: "plógole de facer Duque, é que se llamase Duque de Arjona aquel lugar de se había fecho merced"61.

Asimismo, en una fecha cercana a la obtención de la villa de Arjona, compró la villa de Jódar. Tradicionalmente, siguiendo a Gonzalo Argote de Molina, se ha dicho erróneamente que Luis Méndez de Sotomayor había vendido la villa a Ruy López Dávalos $^{62}$. Sin embargo, lo más probable es que el que vendiera Jódar al condestable fuera Juan Alfonso de Guzmán, que fue señor de esta villa, posiblemente desde 1368, fecha en que Pedro I otorgó a Juan Alonso de Guzmán, conde de Niebla, todos los bienes que don Enrique Enríquez tuvo en Andalucía, entre los que se encontraba Jódar, y que en 1394 seguía aún en su poder. Es muy probable que la venta se efectuara poco después, ya que en el testamento de Juan Alfonso de Guzmán, realizado en 1396, esta villa ya no figuraba entre sus propiedades ${ }^{63}$. Jódar debió de convertirse en una de las localidades más importantes para el condestable, de ahí que surgiera el rumor de que en los sótanos de su castillo hubiera almacenado una ingente cantidad de riqueza. Es posible que fuera mucho menor de lo que se suponía, o que el tesoro que acumuló estuviera en otro sitio, porque la realidad es que cuando se le confiscaron sus bienes, lo que encontraron en la fortaleza de Jódar fue 900 marcos de plata en vajilla y algunas cosas de poco valor ${ }^{64}$.

Su señorío en tierras jiennenses lo completó con la adquisición de otras localidades, como parte de Ibros, que compró en 1395 a Día Sánchez Portocarrero por 2.000 doblas de oro castellanas ${ }^{65}$, y que posteriormente entregó como dote a su hija Leonor Dávalos ${ }^{66}$. También obtuvo La Higuera, tres cuartas partes de Jimena y la vecina Recena, de las que no tenemos constancia ni de la forma ni de la fecha de su obtención ${ }^{67}$. Cerca de Arjona controlaba también el lugar de Alharilla que, según el reparto de bienes que realizaron sus hijos, pertenecía a doña Constanza de Tovar ${ }^{68}$, tercera y última esposa del condestable ${ }^{69}$.

\footnotetext{
61 García de Santa María, Crónica de Juan II, p. 321.

62 Argote de Molina, Nobleza de Andalucía, p. 510.

63 Carmona Ruiz, "Los avatares", pp. 179-180.

64 García de Santa María, Crónica de Juan II, p. 291.

65 1395, diciembre 10. Novalvos (Toledo). AGA, Santisteban, 046-003. En el documento se indica que compró "toda la heredat, vasallos, bienes, con sus términos, fueros e derechos, e con la jurediçión çivil e criminal alta e baxa, e con el juro, mero mixto imperio, que yo he en Ybros, e me perteneçen e pertenesçer deuen en qualquier manera, e segunt mejor e más complidamiente pertenesçieron e pertenesçían a doña Teresa de Biedma”. Esta Teresa de Biedma era la madre de Día Sánchez de Portocarrero. CARmonA Ruiz, "Nuevos datos", donde además de estudiar esta venta se publica el documento, pp. 148-149.

66 Argote de Molina, Nobleza de Andalucía, p. 619. Carmona Ruiz, "Nuevos datos”, p. 137.

67 Galíndez de Carvajal, Crónica de Juan II, p. 418.

68 Era hija de Sancho Fernández de Tovar, guarda mayor de Enrique III, y Teresa de Toledo.

69 Argote de Molina, Nobleza de Andalucía, p. 667.
} 
Por otro lado, Argote de Molina, al hacer referencia al enfrentamiento en Úbeda entre los Aranda y los Trapera, y la posterior huida de los Aranda de Úbeda, comenta que éstos se refugiaron en Bedmar, Jimena y Jódar, villas que pertenecían al condestable ${ }^{70}$. Sin embargo esto no parece ser totalmente cierto, ya que, aunque, como hemos visto, tanto Jimena como Jódar fueron de su propiedad, no así Bedmar, que era una encomienda santiaguista que existía tanto antes como después de que don Ruy López Dávalos fuese señor de Arjona $^{71}$. Es muy probable que ejerciera su influencia en esta encomienda a través de sus parientes, caso de Luis López de Mendoza, quien, como hemos visto, fue corregidor de Úbeda, regidor en Jaén y comendador de Bedmar. Además, en el reparto de sus bienes no se hacía ninguna referencia a esta localidad.

Con esta serie de adquisiciones el condestable conseguía el control de una parte importante del reino de Jaén ya que, además, como hemos visto, tuvo notable influencia a través del corregimiento de Baeza y Úbeda en dos de las ciudades más importantes del reino.

Dentro del territorio andaluz, otra zona en la que ejerció su jurisdicción fue en la frontera del reino de Sevilla, donde en 1401 Enrique III concedió al condestable la villa de Arcos de la Frontera, perteneciente al concejo de Sevilla, a cambio de la entrega a la ciudad de 36.000 maravedís anuales situados en la renta de la sal, lo que la ciudad aceptó ${ }^{72}$. No obstante, esta decisión no fue bien acogida por el concejo arcense, que, sin ningún éxito, solicitó mantenerse bajo la jurisdicción de Sevilla alegando para ello su especial situación fronteriza ${ }^{73}$. En fecha desconocida, cerca de Arcos, e igualmente localizados en la zona fronteriza del reino de Sevilla con Granada, Ruy López Dávalos obtuvo otros castillos, caso de Lopera, que pertenecía al concejo de Sevilla y el de Gigonza, propiedad de Jerez de la Frontera ${ }^{74}$, así como la Torre de Alháquime ${ }^{75}$, recibiendo esta última posiblemente poco después de su conquista, en 1407.

\footnotetext{
$70 \quad$ Ibid. p. 570.

71 Quesada Quesada, La Serranía, p. 118.
}

72 1401?, febrero, 20. Sevilla. El concejo de Sevilla acata la cesión que el rey ha hecho de la villa de Arcos de la Frontera a Ruy López Dávalos por 30.000 maravedíes anuales situados en la renta de la sal. AHNOB, Osuna, CP.65, D.30 y C.116, D.23-24. Sobre la concesión de Arcos de la frontera a Ruy López Dávalos vid. RoJAs GABRIEL, "La señorialización”, p. 140.

73 por la grandeza della e el asentamiento noble de grant fortaleza que tiene de cosa real por el logar onde está asentada e çerca de quien, e por ser puerta e çerradura de todos los males e bienes de toda esta tierra que se fazen de tierra de moros. 1401, agosto, 7. AHNOB, Osuna, CP.65, D.21 y C.116, D. 34-35. Estas quejas continuaron los meses siguientes, teniendo que desplazarse dos veces el alguacil mayor de Sevilla para que Ruy López Dávalos pudiera hacer efectiva la posesión de la localidad. ROJAS GABRIEL, "La señorialización”, p. 140.

74 Lo sabemos a través del documento de cesión a Alonso Enríquez de Arcos, Lopera y Gigonza. 1423, agosto, 14. Tordesillas. AHNOB, Osuna, C. 496, D. 28. Es posible que el concejo de Sevilla construyera la torre de Lopera en el primer tercio del siglo XIV. A finales del siglo XIV pertenecía a Guillén Alfonso de Villafranca, posiblemente por donación de Enrique II, pasando tras la muerte de su hijo, Alfonso Guillén de Villafranca, a manos del concejo de Sevilla. Molina Rozalem, "Una fortaleza", p. 515. Respecto a Gigonza, había estado vinculado a Arcos de la Frontera hasta que entre principios del siglo XIV y 1333 pasó a formar parte del alfoz de Jerez de la Frontera. Martín Gutiérrez, La identidad rural, pp. 122-123. 75 Galíndez de Carvajal, Crónica de Juan II, pp. 418-19. 
Otro espacio en el que ejerció su influencia fue el obispado de Ávila, donde, además, y como ya se ha señalado, ejerció de corregidor de la ciudad. De hecho, poco después de la mayoría de edad de Enrique III, el monarca le hizo donación de un extenso señorío, de más de 1.200 Kilómetros cuadrados, localizado en el sector meridional del alfoz abulense. Hasta 1393 era un amplio espacio que estaba comprendido dentro del concejo de Ávila pero que, en ese año, durante las Cortes de Madrid, el monarca lo desgajó de la ciudad, convirtiendo en villas independientes varias aldeas y ampliando en algunos casos sus términos con los de otras localidades colindantes. Así, se convirtieron en villas La Puebla de Naciados; Castillo de Bayuela; La Adrada; Candeleda, que recibió además el lugar de Las Casillas; Arenas de las Ferrerías (actual Arenas de San Pedro), con los lugares de Ramacastañas, Alasdellano y Alasdelhoyo; y El Colmenar de las Ferrerías (actual Mombeltrán), con los lugares de Las Torres, Lanzahíta y Serranillos. Para ello, el 14 de octubre de 1393, Enrique III expidió seis privilegios de concesión de villazgo, de los que se conservan cuatro (los de Candeleda, Arenas de San Pedro, La Adrada y Mombeltrán), con un contenido muy parecido. Según se indica en ellos, la razón principal de esta concesión es la búsqueda de un mejor poblamiento, dándoles posibilidad de crear nuevas aldeas en su términos, además de una serie de facultades, atribuciones y competencias jurídicas, como la elección de sus autoridades y jueces, la desvinculación total del concejo de Ávila, la celebración de mercado semanal y una feria anual, en todas las villas a excepción de Candeleda, y la exención del pago de algunos impuestos, como el yantar, portazgos, pasajes y peajes por los bienes que transportaran el reino ${ }^{76}$.

No sabemos exactamente la fecha de la concesión de este extenso señorío al condestable, pero es de suponer que se debió de producir poco después de que estas villas fueran desgajadas del alfoz abulense y que los privilegios que recibieron realmente estaban preparando esa donación. De hecho, se conserva un documento de julio 1394, en el que, perteneciendo ya la villa de El Colmenar de las Ferrerías a López Dávalos, Enrique III reitera a la villa el privilegio de exención del pago de portazgo, pasaje y peaje ${ }^{77}$. Lógicamente todo este proceso tuvo que contrariar bastante al concejo de Ávila, que no lo aceptó hasta junio de $1395^{78}$. Además le donó las tercias de todas estas localidades ${ }^{79}$. Los beneficios económicos que obtuvo don Ruy de estos señoríos son indudables. Su localización a caballo de ambas mesetas, con el Puerto del Pico como paso natural, controlado por Mombeltrán, que cobraba derecho de tránsito de personas y mercancías debió de beneficiarlo notablemente. Asimismo, era zona de trasiego de ganados

\footnotetext{
76 1393, octubre, 14. Madrid. GonzÁlez, Colección de privilegios, publica los de Mombeltrán, La Adrada y Candeleda, docs. CXXXVII al CXXXIX, pp. 419-424. El de Mombeltrán está publicado también por Barrios y otros, Documentación Medieval, doc. 7, pp-23-29 y los de Candeleda y Arenas de San Pedro por Luis López, Documentación medieval, docs. 7 y 8, pp. 80-89. Un estudio de este proceso en LuIs LóPEZ, "Villazgos señoriales", pp. 111-260.

77 1394, julio, 6. Valladolid. Barrios y otros, Documentación Medieval, doc. 8, pp. 27-29.

78 1395, junio, 5. Cit. Dávalos y Ayala, Vida, hechos ilustres, fols. 79v-80r. Ariz, Historia de las grandezas. $3^{\text {a }}$ Parte, fol. $24 \mathrm{v}-25 \mathrm{r}$.

79 García Luján, Libro de "Lo Salvado", p. 276.
} 
trashumantes y, de hecho, en la aldea de Ramacastañas, el ganado pagaba el servicio y montazgo ${ }^{80}$. Además, el monarca en 1395 Enrique III le donó varias dehesas, que posiblemente se dedicaban a ese tipo de ganado, una localizada en Lanzahíta (lugar de El Colmenar de las Ferrerías), otra en El Llano (La Adrada) ${ }^{81}$. También se aprovechó de las explotaciones mineras de la zona de Los Llanos, gracias a la propiedad de varias herrerías en Candeleda y en Arenas de San Pedro ${ }^{82}$.

Fuera de estos dos grandes sectores, adquirió también otros territorios. Tenemos cierta información de algunos, y es muy probable que poseyera más. Así compró a Pierre de Villaines, compañero de Bertrand du Guesclin, el condado de Ribadeo, con la puebla de Navia, con ayuda de 100.000 maravedís que le legó el arzobispo de Toledo Pedro Tenorio en su testamento, elaborado en $1398^{83}$. Esta transacción la debió de realizar hacia 1401, fecha en que Pierre de Villaines a su regreso a Francia adquirió la ciudadestado de Yvetot, para lo que empleó el dinero de la venta del condado ${ }^{84}$.

Asimismo, en 1399 adquirió el lugar de Santiago de la Puebla, localizado en el obispado de Salamanca, a Sancho de Rojas, entonces obispo de Palencia y a su hermano Martín de Rojas, "con sus aldeas e términos, e la justiçia e pechos e derechos". Se conserva la escritura de compraventa, realizada ante Juan Vélez, escribano del rey y notario público de la corte, en la que sólo aparecen los vendedores, ya que Ruy López Dávalos no estaba presente. Según se indica en el propio documento, éste había pagado previamente 5.000 florines de oro aragoneses, y si costara más "vos lo damos en pura e justa donaçión fecha entre biuos por muchas ayudas e buenas obras que de uso reçebimos". En el mismo pergamino, y a continuación, Martín de Rojas realizó una carta de aceptación de la venta, debido a que era menor de 25 años y mayor de $14^{85}$.

Sin embargo, este señorío no estuvo en manos de Ruy López Dávalos mucho tiempo, ya que esta venta fue revocada en 1404, fecha en que se anulaba la compra y se devolvía al condestable la misma cantidad de dinero que había invertido ${ }^{86}$. En esta ocasión sí estaba presente el condestable, y en ningún momento se indica la razón por la que se deshizo el acuerdo. Afortunadamente se ha conservado un documento relacionado con este señorío que nos puede dar alguna luz sobre esta cuestión. Se trata de una confirmación de Enrique III realizada en 1406, de la licencia que en 1397 el mismo monarca había dado a Sancho de Rojas para vender la posesión de Santiago de la Puebla a su hermano Martín. Según se indica, Juan I había dado en señorío esa localidad a Juan

\footnotetext{
80 Tejero Robledo, Arenas de San Pedro, p. 26.

81 1395, diciembre, 6. Madrid. AHPZ - P/4-100-4.

82 Tejero Robledo, "Emergencia del Valle", p. 27.

83 1398, noviembre, 4. Alcalá de Henares. Este dinero era parte de una asignación de 200.000 maravedíes que Enrique III había dado al arzobispo, pagaderas en dos años. Por ello estipula que destos cien mil maraudís deste año fezimos gracia a Rui Lopez Daualos Camarero del dicho señor Rey, e su Adelantado mayor del Reyno de Murcia, para ayuda de la comprar del Condado de Ribadeo. Edit. Narbona. Historia de D. Pedro Tenorio, fol. 129v. Dávalos y Ayala, Vida, hechos ilustres, fol. 86r.

84 Paraje Méndez, El condado de Ribadeo, p. 444.

85 1399, junio, 15. Segovia. AHNOB, Baena, C. 340, D. 62.

${ }^{86}$ 1404, abril, 3. Medina del Campo. AHNOB, Baena, C. 340, D. 63.
} 
Martínez de Rojas, II señor de Monzón y padre del eclesiástico, y lo había heredado don Sancho con la condición de que sólo la pudiera vender con autorización real ${ }^{87}$. Sabiendo que en 1399 en la venta a López Dávalos participaron los dos como copropietarios, hay que suponer que no transmitió a su hermano toda la propiedad sino parte. Enlazando todo esto con el problema que nos atañe, planteamos la posibilidad de que la venta del señorío se hubiera hecho sin la autorización real pertinente, establecida en el privilegio de donación, y de ahí que se tuviera que revertir la venta. Ello puede explicar que en el documento de retroventa entre los testigos figurara el infante don Fernando de Antequera, actuando quizás como representante del rey. Por otro lado, resulta interesante que Sancho de Rojas solicitara una confirmación de la autorización de venta a su hermano en 1404, aunque en 1415 el propio obispo vendía ese señorío a Juan Álvarez de Osorio ${ }^{88}$. Esta venta se debió anular también, ya que en 1421, siendo ya arzobispo de Toledo, Sancho de Rojas se lo donaba a su sobrino Juan de Rojas, alcalde mayor de los hijosdalgos de Castilla $^{89}$. El arzobispo de Toledo debía de ser consciente de la irregularidad de todas estas transacciones y, por lo tanto, de que los acuerdos podían ser anulados, lo que nos lleva a plantear la hipótesis que más que ventas reales, pudieran ser una forma de recibir préstamos con interés encubierto, un censo consignativo, sirviendo las rentas de la localidad como forma oculta de pagar ese interés, de ahí que las ventas se revirtieran por el mismo valor de compra ${ }^{90}$.

Menos información tenemos de otros señoríos que el condestable tuvo, como es el caso de Osorno ${ }^{11}$. Sara Rodicio supone, sin dar muchos argumentos, que entró en el patrimonio del condestable a través de su matrimonio con doña Elvira de Guevara, su segunda esposa, que era hija de Beltrán de Guevara, señor de Oñate ${ }^{92}$. Posteriormente, entregó esta localidad a su hija Mencía como dote por su matrimonio con Gabriel Manrique de Lara, hijo del Garcí Fernández Manrique, conde de Castañeda y de Aguilar de Campoo ${ }^{93}$. Además de controlar estos señorío, también sabemos que Ruy López Dávalos fue señor de Alija y de la mitad de Villabarba, aunque solo nos consta su propiedad a través del reparto que hicieron sus hijos en $1440^{94}$.

87 1397, septiembre, 13. La confirmación es de1406, septiembre 11. Valladolid. AIVDJ, A-9/6.

88 1415, mayo 13. Valladolid. Sancho de Rojas Gabriel ordena al concejo de la Puebla de Santiago que acepten a Juan Álvarez de Osorio como su señor. AHNOB, Baena, C. 45, D. 20.

89 1421, agosto, 4. Arévalo. AHNOB, Baena, C. 45, D. 21-22.

90 Sobre esta temática vid. Rico Callado, "Los censos consignativos en Castilla"; Carvajal de la Vega, "Crédito privado en Castilla".

91 García de Santa María, Crónica de Juan II, p. 321. Galíndez de Carvajal, Crónica de Juan II, p. 425; Argote de Molina, Nobleza de Andalucía, pp. 667-668. Dávalos y Ayala, Vida, hechos ilustres, fol. $176 \mathrm{v}-177 \mathrm{r}$.

92 Rodicio García, “Osorno y su condado” p. 345.

93 Ibid, p. 234.

94 Argote de Molina, Nobleza de Andalucia, pp. 667-668. Dávalos y Ayala, Vida, hechos ilustres, fol. $176 \mathrm{v}-177 \mathrm{r}$. 
Por otro lado, Juan Dávalos y Ayala dice que cuando Enrique III confiscó la villa de Paredes de Nava a Pedro Enríquez, conde de Trastámara “dióla a Ruy López Dáualos"95, aludiendo quizás a su control militar. Siguiendo esta noticia algunos autores consideran que esta localidad fue señorío del condestable. En todo caso, si llegó a ejercer como señor de esa villa, cosa que dudamos, fue por poco tiempo, ya que Enrique III se la devolvió después a Pedro Enríquez, para finalmente entrar a formar parte del señorío de su hermano, el infante don Fernando de Antequera ${ }^{96}$.

\section{Cuadro 2}

\section{Señoríos de Ruy López Dávalos}

\begin{tabular}{|l|l|l|}
\hline Señoríos & Fecha & Forma de Adquisición \\
\hline - Arjona (Jaén) & 1394 & Donación real \\
\hline - Arjonilla (Jaén) & 1394 & Donación real \\
\hline - La Higuera (Jaén) & Desconocida & Desconocida \\
\hline - - /4 de Jimena (Jaén) & Desconocida & Desconocida \\
\hline - Jódar (Jaén) & $1395 ?$ & Compra \\
\hline - Recena (Jaén) & Desconocida & Desconocida \\
\hline - 1/2 de Ibros (Jaén) & 1395 & Compra \\
\hline - Alharilla (Jaén) & Desconocida & $\begin{array}{l}\text { Era de Constanza Tovar, } \\
\text { su mujer }\end{array}$ \\
\hline - Arcos de la Frontera (Cádiz) & & Donación real \\
\hline - Torre de Alháquime (Cádiz) & 1401 & Donación real \\
\hline - Torre de Lopera (Utrera, Sevilla) & 1407 & Desconocida \\
\hline - Castillo de Gigonza (San José del Valle, Cádiz) & Desconocida & Desconocida \\
\hline - Arenas de San Pedro (Ávila) & $1394 ?$ & Donación real \\
\hline - El Colmenar (Ávila) & $1394 ?$ & Donación real \\
\hline - Castillo de Bayuela (Ávila) & $1394 ?$ & Donación real \\
\hline - Las Adrada (Ávila) & $1394 ?$ & Donación real \\
\hline - Candeleda (Ávila) & $1394 ?$ & Donación real \\
\hline - La Puebla de Naciados o de Santiago (Ávila) & $1394 ?$ & Donación real \\
\hline - Alija (León) & Desconocida & Desconocida \\
\hline - Santiago de la Puebla (Salamanca) & $1399-1404$ & Compra \\
\hline - - 1/2 Villabarba (Valladolid) & Desconocida & Desconocida \\
\hline - Osorno (Palencia) & Desconocida & Desconocida \\
\hline - Ribadeo (Lugo) & $1401 ?$ & Compra \\
\hline - Navia (Oviedo) & $1401 ?$ & Compra \\
\hline & & \\
\hline
\end{tabular}

95 Dávalos y Ayala, Vida, hechos ilustres, fol. 64r. Este dato lo recoge Ruano Prieto, "El condestable", VIII, p. 117, y posteriormente otros autores que han utilizado estos trabajos.

96 Un estudio sobre esta problemática en MuÑoz GómEZ, "La adquisición de dominios señoriales" y $E l$ poder señorial de Fernando "el de Antequera", pp. 155-158. 


\subsection{Propiedades inmobiliarias}

La información relativa a las propiedades inmobiliarias que Ruy López Dávalos llegó a acumular es todavía más parca que la relacionada con su patrimonio señorial, y en su mayor parte procede de los escuetos datos vinculados al reparto de sus bienes. Esa hacienda estaba compuesta tanto por bienes rústicos como urbanos, localizados casi todos en lugares vinculados a sus señoríos o a su actividad política. Sabemos que tenía varias casas repartidas por todo el territorio castellano, de algunas sólo conocemos la existencia, de otras tenemos cierta información. Así, mantuvo residencias en algunas de las villas de sus estados señoriales, destacando en este sentido las de Arenas de San Pedro, Arjona y Jódar, que se convirtieron en los lugares de vivienda más habituales. Fue precisamente en el castillo de Arenas de San Pedro, donde se mantuvo cuando, por orden de Enrique III en 1400 sufrió el destierro de la Corte durante unos meses ${ }^{97}$, era en la fortaleza de Jódar donde se suponía que guardaba notables riquezas, y fue en Arjona donde buscó refugio tras huir después del sitio de Montalbán ${ }^{98}$. Pero también, sabemos que tenía otros inmuebles en otras localidades, caso de Córdoba, Ávila, Valladolid, Úbeda y Toledo.

De las casas de Ávila, tan sólo tenemos constancia a partir del ya citado reparto que sus hijos realizaron en 1440. De la de Córdoba sólo sabemos que estaba localizada en la collación de San Bartolomé ${ }^{9}$. En relación a la de Valladolid, sabemos que Catalina de Lancaster tenía unas casa y huertas que regaló al condestable en 1398. No obstante, no estuvieron en poder de éste mucho tiempo, puesto que en 1407 las donó a los agustinos para que instalaran allí su convento, incluyendo además otra huerta colindante que poseía $^{100}$. Sin embargo, no está muy clara la legitimidad de toda esta transacción, ya que, en 1416 los monjes del monasterio de Santa María la Real de Nieva iniciaron un pleito contra el convento de San Agustín de Valladolid, acusándole de haber construido el monasterio en unas tierras que les pertenecían y que ilegalmente le había donado el condestable. Ante ello, por orden de la reina y como compensación, éste donó al monasterio de Santa María 3.000 maravedís de renta procedente de la cabeza de pecho de la aljama de los judíos de Segovia ${ }^{101}$. No quedaron conformes los monjes de Nieva

\footnotetext{
97 Argote de Molina, Nobleza de Andalucía, p. 559. Este autor suponía que este destierro fue de tres años, pero duró bastante menos, ya que en las Cortes de Toledo de 1402 estaba presente en la actividad política. Mitre Fernández, Evolución de la nobleza, p. 45, y anteriormente había participado en la pacificación de Úbeda, como hemos visto.

98 Galíndez de Carvajal, Crónica de Juan II, p. 415 y p. 417.

99 Archivo Catedral de Córdoba, colección Vázquez Venegas, vol. 273, fol. 180v. González Sánchez, La Corona de Castilla, p. 2034.

100 1407, abril, 28, Valladolid. Donación de Ruy López Dávalos y su mujer Elvira de Guevara. 1398, mayo 31. Confirmación de Enrique III de la donación de Catalina de Lancaster a Ruy López Dávalos de las casas y huerta, que anteriormente habían sido de Juan Núñez, despensero de Juan I. 1398, octubre 14, Valladolid. Donación de Mondisón Bernal a Ruy López Dávalos de una huerta situada junto a esa casa. Floranes, "Noticias del convento de San Agustín", pp. 476-478. De este convento actualmente solo queda la iglesia, que es la sede del Archivo Histórico Municipal.

101 1416, septiembre, 16. Valladolid. Floranes, "Noticias del convento de San Agustín”, p. 479.
} 
con esta solución, por lo que continuaron con el proceso, hasta que en 1421 López Dávalos les cedió 4.000 maravedís de renta anual en un juro que tenía en Carrión ${ }^{102}$.

Con respecto a Úbeda, mantuvo casa abierta, no sólo por ser oriundo de esta ciudad, sino también por su actividad política en ella. Así, sabemos que en esta residencia ${ }^{103}$ se criaron Pedro y Diego Ortiz, sobrinos del contador sevillano Nicolás Martínez de Medina, quienes, gracias a su tío y a su vinculación con el condestable vieron favorecida su carrera política y financiera en Sevilla y en la corte ${ }^{104}$. También fue Toledo lugar de residencia habitual y allí fue donde nacieron y se asentaron algunos de sus hijos ${ }^{105}$. Ruy López Dávalos tuvo además numerosos inmuebles urbanos en otras localidades castellanas ya que, en julio de 1392, Enrique III le concedió los bienes de las aljamas y sinagogas del arzobispado de Toledo y del obispado de Córdoba, salvo los de Villarreal, que el rey entregó a Gonzalo de Soto, maestresala del rey. Además, recibió los bienes de los judíos exiliados y de los conversos que tras el pogromo de 1391 habían abandonado el reino para volver a su antigua religión, en todo el territorio de la Corona de Castilla, con especial mención de Toledo, Córdoba y Sevilla. Estos privilegios los confirmó el monarca en febrero de 1394, poco después de salir de la minoría ${ }^{106}$.

Así pues, debió de obtener un importante capital, teniendo en cuenta que recibió los bienes de las dos aljamas más importantes del reino, como son Toledo y Córdoba, además de buena parte de las que había en esas diócesis. Además, los asaltos provocaron una notable emigración, dirigida principalmente a Granada y Portugal, por lo que los bienes expropiados a los exiliados tuvieron que ser cuantiosos. En el caso de Sevilla, sabemos que, aunque en un principio el concejo de Sevilla impidió que los conversos y judíos que emigraron pudieran vender sus bienes, en 1392 éstos consiguieron que Enrique III autorizara esas transacciones en el arzobispado de Sevilla y obispado de Cádiz, defendiendo además a quienes hubieran adquirido esas propiedades ${ }^{107}$. Dos meses después el monarca protegía también a los conversos que salían del reino con fines comerciales impidiendo que se les embargaran sus bienes ${ }^{108}$.

\footnotetext{
102 1421, abril, 12. Ocaña. Floranes, "Noticias del convento de San Agustín”, p. 480.

103 Hay autores que, sin ninguna constancia documental, consideran que esta casa estaba localizada en el mismo solar donde en el siglo XVI el capitán Andrés Dávalos de la Cueva, caballero de Santiago, realizó su palacio, denominado popularmente como "casa de las Torres", situada en el barrio de San Lorenzo. Molina Hipólito, Guía de Úbeda.

104 Montes Romero-Camacho, "El converso sevillano", p. 349. La actividad como alcabalero de Pedro Ortiz en Vilaplana Montes, "Un ajuste de cuentas del alcabalero".

105 Martz, A Network, pp. 158 y 332.

106 1392, julio 29. Burgos. Confirmación en 1394, febrero, 4. Illescas. AMS, secc. I, carp. 107, nº 1. Edit. Collantes de Terán, “Un pleito sobre bienes”, pp. 181-183. Sobre la entrega de los bienes de los judíos de Villarreal, Delgado Merchán, Historia documentada, pp. 137-138.

107 1392, marzo, 12. Burgos. AMS, secc. I, carp. 107, nº 1. Edit. Collantes de TerÁn, "Un pleito sobre bienes", p. 180, doc 1 .

108 1392, mayo, 28. Burgos. AMS, secc. I, carp. 107, nº 1. Edit. Collantes de Terán, "Un pleito sobre bienes", p. 181, doc 2 .
} 
Todo esto se producía poco antes de la concesión a Ruy López Dávalos de los bienes de las aljamas y sinagogas del arzobispado de Toledo y del obispado de Córdoba y de los conversos exiliados y retornados al judaísmo. Tras este privilegio los conversos tuvieron bastantes problemas para vender sus propiedades, ya que había bastante incertidumbre y temor a que, tras su compra, el nuevo propietario las pudiera perder. Por ello, Enrique III, poco después de confirmar la donación al condestable, escribió al concejo de Sevilla, ordenándole que garantizasen y respetasen las ventas que los conversos realizaban ${ }^{109}$. Tal vez buscando esa garantía, y a fin de evitar la indefensión de los posibles compradores, el concejo de Sevilla ordenó que todos los conversos que quisieran vender sus casas deberían de presentar fiadores que garantizaran que iban a vivir en sus lugares habituales los seis años siguientes. Si se iban antes y vendían, esos bienes pasarían a ser propiedad de López Dávalos, embargándoselos al comprador ${ }^{110}$. Este pregón debió de alentar la realización de transacciones con los conversos, aunque es muy probable que algunas fueran irregulares. Ello explica que don Ruy denunciara algunas ventas ilegales, por lo que en mayo de 1394 el rey nombraba a Pedro López, oidor de la audiencia real, juez de todos los pleitos que se instruyeran en el reino de Sevilla relacionados con este problema ${ }^{111}$.

De toda esta situación tenemos constancia a partir de uno de los pleitos que se produjo a raíz de la venta de unas casas de un converso al que Ruy López Dávalos denunció en 1396, del que se conserva una copia de las actuaciones que se llevaron a cabo a lo largo del proceso ${ }^{112}$. En este caso la denuncia era contra Juan Martínez, jurado y escribano público de Sevilla, al que se le acusó de comprar ilegalmente unas casas en la collación de San Bartolomé a Yusaf Abravaniel, que como converso se llamaba Pedro González, y que se había marchado "a tierra de moros, e vsa allí como judío" por lo que consideraba que debía perder todos los bienes en beneficio de López Dávalos. La sentencia del juez Pedro López fue absolutoria, basándose en que la compra de esas casas se realizó antes que el pregón de los alcaldes mayores de 1394, al que hemos hecho referencia ${ }^{113}$, en que se ponía como condición que los conversos que quisieran vender sus casas deberían de presentar fiadores que garantizaran que iban a vivir en sus lugares habituales los seis años siguientes ${ }^{114}$.

Entre las propiedades inmuebles que debió de adquirir en diferentes localidades castellanas, sabemos que tuvo algunos edificios de carácter industrial, como es el caso de las herrerías que tenía en Candeleda y en Arenas de San Pedro, como hemos visto, o unas aceñas, situadas en el río Guadalete. También poseyó otros bienes rústicos, muchos

109 1394, febrero, 24. Alcalá de Henares. AMS, secc. I, carp. 107, no 1. Edit. Collantes de Terén, "Un pleito sobre bienes", p. 184, doc 5 .

110 1394, marzo 27. AMS, secc. I, carp. 107, no 1. Edit. Collantes de Terán, "Un pleito sobre bienes", doc. 6 , pp. 184-185.

111 1392, mayo, 9, Toledo. AMS, secc. I, carp. 107, $\mathrm{n}^{\circ} 1$.

112 Todo ello ha sido estudiado por Collantes De TeRÁn, "Un pleito sobre bienes".

113 1394, marzo 27. AMS, secc. I, carp. 107, no 1. Edit. Collantes de Terán, "Un pleito sobre bienes", doc. 6, pp. 184-185.

${ }^{114}$ Sentencia de Pedro López de 1396, junio, 9. AMS, secc. I, carp. 107, no 1. 
localizados en sus señoríos, aunque también en otras localidades, algunos de los cuales conocemos a través del reparto de sus bienes que simularon sus descendientes en 1440 . Así, como se puede ver en el cuadro 3, dispuso de varias heredades y haciendas, de las que tan sólo conocemos la localidad en las que estaban situadas y de las que desconocemos su extensión, tipo de explotación o localización concreta. Además, y como hemos visto, disfrutó de varias dehesas que en 1395 le donó Enrique III, en Lanzahíta y en El Llano. Estas tierras pertenecían a Urraca González, que las había recibido de su padre Blasco Jiménez, señor de Navamorcuende ${ }^{115}$. En compensación, Enrique III entregó a esta señora la localidad de La Puebla de la Horcajada (Segovia), que, según se indica en el documento de donación, "estaba yerma", por lo que la recibió para usarla como dehesa, privilegio que posteriormente le confirmó Juan II ${ }^{116}$.

Ruy López Dávalos tuvo además otros bienes de naturaleza incierta, de los que conocemos algunos, pero que debido a la imprecisa descripción que se hace de ellos, desconocemos su tipología.

\section{Cuadro 3}

\section{Propiedades inmobiliarias}

\begin{tabular}{|l|l|}
\hline - Herrerías en Candeleda & - Casas en Arenas de San Pedro (Ávila) \\
- Herrerías en Arenas de San Pedro & - Casas en Ávila \\
- Dehesas en Lanzahíta & - Casas en Toledo \\
- Dehesas en El Llano (Ávila) & - Casas y huertas en Valladolid \\
- Heredamiento en Ávila & - Casas en Córdoba \\
- Heredad de Madrigal (Ávila) & - Casas en Úbeda \\
- Heredad de Alharaz & - Casas en Arjona \\
- Hacienda en Carrión (Palencia) & - Fortaleza de Jódar \\
- Heredad en Talavera (Toledo) & - Bienes en Mengíbar \\
- Heredades y casas en San Martín de & - Bienes de las aljamas y sinagogas del \\
Valdeiglesias (Madrid) & arzobispado de Toledo y del obispado de \\
& Córdoba \\
- Heredades en la Puebla de Alcocer & - Bienes de los judíos exiliados \\
- Aceñas en el Guadalete & - Bienes de los conversos exiliados que habían \\
- Hacienda en Sevilla & vuelto al judaísmo tras irse de Castilla \\
\hline
\end{tabular}

\subsection{Rentas y otros beneficios económicos}

Junto a las ventajas económicas que le reportaron sus señoríos a través de diversos tipos de imposiciones, desde muy pronto empezó a acumular numerosas rentas de muy diversa índole y procedencia, cedidas principalmente por Enrique III, pero también por otros monarcas. Así, en 1394 el rey Carlos III de Navarra le donaba todas las rentas

\footnotetext{
115 Reviejo PAZ, La casa, p. 152, nota 481.

116 1395, diciembre, 6. Madrid. Juan II confirma la donación en 1408, mayo, 3. Alcalá de Henares. AHPZ - P/4-100-4. AHPZ - P/4-100-4
} 
ordinarias de Lerín y Ávalos, como recompensa por sus servicios al monarca, a cambio de vasallaje al rey navarro y el compromiso de apoyarle contra cualquier persona contra la que se enfrentara, a excepción del rey de Castilla ${ }^{117}$. Esta merced posiblemente esté relacionada con la negociación de la vuelta de su mujer, Leonor, a Navarra, y vinculada al deseo Carlos III de acercarse al rey de Castilla a través de personajes próximos a éste, de manera que, además de Ruy López Dávalos, Diego López de Zúñiga y Juan Hurtado recibieron importantes beneficios del rey navarro ${ }^{118}$. Tenemos alguna información sobre la percepción de estas rentas, y así, de Lerín hay datos entre los años 1399 y 1418, en los que generalmente recibía 113 libras fuertes, junto con 500 cahíces de pan, mitad trigo, mitad cebada, de los que se descontaba la tercera o cuarta parte, dependiendo el año ${ }^{119}$. En el caso de Dávalos, sabemos que en 1399 percibió 17 sueldos y 6 dineros por la fonsadera, y por la pecha, 17 libras y 19 dineros óbolos, más 37 cahíces y 2 robos de trigo y otros tantos de cebada ${ }^{120}$.

Los encargados del cobro de estas rentas fueron algunos delegados del condestable, y así, sabemos que varios años las recibió un familiar suyo, Juan Dávalos ${ }^{121}$, aunque en otros fue el judío Isaac de Mijancas, el que las percibió ${ }^{122}$. En el año 1403, ante la queja de los vecinos de Lerín debido a la situación ruinosa de la localidad a consecuencia de las epidemias y malas cosechas, Carlos III les eximió del pago de la quinta parte de su obligaciones con el condestable ${ }^{123}$. Además, debió de recibir otras mercedes del rey de Navarra de carácter puntual ${ }^{124}$.

Uno de los beneficios más lucrativos que obtuvo de Enrique III fue la renta de las almonas o jabonerías del arzobispado de Sevilla y obispado de Cádiz. En un principio,

117 1394, julio, 31. Pamplona. AGN Comptos, c. 70, no 34. Mitre Fernández. Evolución de la nobleza, pp. 95-96.

118 González SÁnchez, Las relaciones exteriores, p. 111.

119 Los años 1404, 1405, 1406, se le descuenta la cuarta parte, los años 1407, 1416, 1418, la tercera parte. Los años 1399 y 1401 no se indica que se descuente ninguna cantidad. AGN, Comptos. CAstro, Archivo General de Navarra, Tomos 23 (docs. 517 y 920), 24 (doc. 462), 25 (doc. 496), 26 (docs. 589 y 1330), 27 (doc.165) y 32 (docs. 160 y 1053).

120 1399, octubre, 18. AGN, Comptos, C. 77, 55. CASTRo, Archivo General de Navarra, tomo 23, $\mathrm{n}^{\circ} 517$.

${ }_{121}$ Según se indica en el poder que Ruy López Dávalos firmó en 1395, Juan Dávalos era escudero y familiar suyo. AGN, Comptos, c. 70, no 6. CAStro, Archivo General de Navarra, Tomo 21, doc. 45. Además de en 1395, Juan Dávalos percibió esta renta en 1416, 1418 y 1419. AGN, Comptos, c. 105, n ${ }^{\text {os }} 6$ y15. CASTro, Archivo General de Navarra, Tomo 32, docs. 156, 160, 1053 y 1055.

${ }_{122}$ Isaac de Mijancas era un judío procedente de Vitoria que recaudó esas rentas al menos los años 1399, $1401,1404,1405,1406$ y 1407. AGN, Comptos, c. $77, \mathrm{n}^{\text {os }} 31$ y 55 ; c. $80, \mathrm{n}^{\circ} 5 ;$ c. $81, \mathrm{n}^{\text {os }} 7$ y $14 ;$ c. $82, \mathrm{n}^{\circ}$ 5; c. 83, no 9. Castro, Archivo General de Navarra, Tomos 23 (docs. 406 y 517), 24 (doc. 462), 25 (doc. 496), 26 (docs. 589 y 1330) y 27 (doc. 165).

${ }^{123}$ AGN, Comptos, caja 89, ${ }^{\circ}$ 60. CAstro, Archivo General de Navarra, Tomo 25, Doc. 531. Mitre FerNÁNDEZ, Evolución de la nobleza, pp. 97-98.

${ }^{124}$ Así, en 1400 Carlos II le entregaba 78 cahices y 3 robos de trigo y otros tantos de cebada, más 35 libras, 17 sueldos y 6 dineros. AGN, Comptos, caja 85, n 47, I. CASTRO, Archivo General de Navarra, Tomo 23, doc. 920. En 1401 le eximía de los derechos del pago del vigésimo y décimo de sus rentas en Lerín y Dávalos, habiéndole concedido esta exención a petición de la mujer del condestable. AGN, Comptos, caja 86, $\mathrm{n}^{\circ}$ 50, IX. CAstro, Archivo General de Navarra, Tomo 24, doc. 455. Mitre Fernández, Evolución de la nobleza, p. 97. 
se la concedió Enrique III para que la percibiera durante tres años, a contar desde enero de 1396, merced que iba en perjuicio de los arrendadores del almojarifazgo de la ciudad de Sevilla, por lo que debieron presentar una queja. Ante ello, en mayo de 1396 el monarca la ratificaba, y además la ampliaba a diez años, convirtiendo en 1397 la cesión en perpetua ${ }^{125}$. El privilegio incluía también la exención de pago de 3 reales de plata por caja del almojarifazgo del jabón blanco de saca por mar y la exclusividad de la fabricación, prohibiendo que se realizaran fábricas que no estuvieran bajo su control. La rentabilidad de este beneficio era notable, y así, en 1423, momento en que Juan II la expropió, obtenía de renta anual por este concepto 165.000 maravedíes ${ }^{126}$. Además, en Sevilla obtuvo otras rentas no menos beneficiosas, como los 200.000 maravedíes "situados" en las tahurerías de Sevilla".

Por otro lado, también obtuvo importantes rentas asociadas a sus señoríos y al ejercicio de la jurisdicción en ellos. Ya hemos visto que junto al señorío de Arjona obtuvo en 1394 las tercias de Arjona ${ }^{128}$ y en 1398 los almojarifazgos de esta villa y del lugar de Isdra $^{129}$. Además, disfrutaba de un juro de 14.207 maravedís y 4 cornados sobre las rentas de Arjona, y 11.850 maravedíes de los fueros y tributos de esta villa y sus lugares ${ }^{130}$.

Asimismo, en el condado de Ribadeo, se beneficiaba desde 1403 de 26.000 maravedíes anuales de las alcabalas, alegando ser ésta la cantidad que había tomado en las rentas el anterior titular del condado, Pierre de Villaines. Del mismo modo, López Dávalos percibía desde 1403 y con carácter anual el importe total de los diezmos de la mar y alfolíes de las villas de Ribadeo y Navia, señalando que le pertenecían por merced real, a pesar de no haber mostrado ante los contadores mayores el privilegio que le habilitaba a la recaudación de las rentas de dichos lugares ${ }^{131}$. Posiblemente, junto al diezmo percibía las rentas del alfolí junto con otros derechos, que ascendían en 1420 a 76.289 maravedíes y 2 cornados, entre los que se incluían las rentas de las escribanías ${ }^{132}$.

\footnotetext{
${ }_{125}$ No conocemos la fecha de la primera concesión, aunque sabemos de su existencia a través del privilegio de donación perpetua realizado en Madrid el 20 de diciembre de 1397. En él se recogen además dos documentos relacionados con ella: un albalá realizado el 23 de mayo de 1396, comunicando a los arrendadores del almojarifazgo de Sevilla la concesión a Ruy López Dávalos de la renta de las almonas, en el que además de ratificar la concesión por tres años, la ampliaba por siete años más, a comenzar en enero de 1396; y un albalá realizado el 11 de diciembre de 1397, en el que notificaba a los contadores mayores y otros oficiales del reino la donación a perpetuidad de la renta de la almona de Sevilla y su arzobispado. AHNOB, C. 496, D. 1. ADM, ducado de Alcalá, 055-016. Joaquín González Moreno utilizó esta información en su libro sobre las almonas sevillanas, mezcla la información. Cfr. GonzÁLEz MorENO, Las reales almonas, pp. 47-48.

126 AHNOB, Osuna C. 496, D. 1 y 2.

127 AHNOB, Osuna C. 286, D. 27.

128 AGS Mercedes y Privilegios, leg. 9, fol. 35, Mitre Fernández, Evolución de la nobleza, p 113.

129 AGS Mercedes y Privilegios, leg. 1, fol. 487, Mitre Fernández, Evolución de la nobleza, p. 118.

130 AGS Mercedes y Privilegios, leg. 7, fol. 100 y leg. 47, fol. 38. GonzÁlez SÁnchez, La Corona de Castilla, p. 329

131 Así, se indica en la relación de embargos que dieron los contadores mayores de las cuentas el año de 1415. AGS Escribanía Mayor de Rentas, leg. 1. Ver también Rubio Martínez, "La Hacienda Real”, p. 467.

132 1420, agosto, 27. Valladolid. RAH, Col. Salazar y Castro, M-62, fols. 52v-55v.
} 
Asociado a su señorío en el obispado de Ávila, también obtuvo numerosas rentas, como hemos visto. Así, Enrique III le donó las tercias de todas localidades ${ }^{133}$, cobraba derechos de tránsito de personas y mercancías en Mombeltrán y en la aldea de Ramacastañas el servicio y montazgo de los ganados trashumantes ${ }^{134}$. Por otro lado, realizó algunas imposiciones arbitrarias y se apropió de otras. Así, aumentó algunos impuestos, como el cobro del noveno y meaja sobre vino, carne y ventas, el cobro de "pasadas" a los temporeros que salían a labrar en tierras de Ávila, o el cobro del pecho de carretas, peones y carbón, y el quinto de los bienes de los que morían sin testar ${ }^{135}$, así como la obligación que impuso a los de Mombeltrán de pagar el carbón de las dos herrerías que tenía en Arenas de San Pedro. También se apoderó de algunos bienes de propios, un "echo" del pinar de Áñez y las pegueras del Sequero, pertenecientes a la villa de Mombeltrán, a cuyos vecinos exigió usar la tenería que había construido ${ }^{136}$. Por otro lado, y para financiar la construcción del castillo de Arenas de San Pedro, impuso a todas sus villas el pedido o pecho de "carretas, peones y carbón", en la siguiente proporción: dos carretas Arenas, cuatro Mombeltrán, una La Adrada, Castillo de Bayuela y Candeleda, y media La Puebla de Naciados. En 1417 permuta cada carreta a razón de 1.800 maravedís cada una ${ }^{137}$.

También disfrutaba de otras rentas en diferentes territorios castellanos, posiblemente de donación real, como las tercias de Tordesillas y su arciprestazgo, incluyendo las de Velliza y Villahán ${ }^{138}$, que junto a los censos de Villena montaban en total 50.580 maravedíes ${ }^{139}$. Además, disfrutaba de las tercias de Paredes de Nava ${ }^{140}$ y percibía también 8.500 maravedíes de las alcabalas de Carrión ${ }^{141}$, los censos de Villena ${ }^{142}$ y 5.000 maravedíes de moneda vieja en las martiniegas de algunos lugares de la merindad de Castrojeriz ${ }^{143}$. Además, gozó de la tenencia de algunos castillos y fortalezas que, además de aportarle importantes beneficios de carácter político y militar, también le reportaron notables ingresos económicos. Así, además de tener en propiedad los castillos situados en sus señoríos, sabemos que ostentó la tenencia de otras fortalezas. Es el caso de la de Alcalá la Vieja, que el arzobispo don Pedro Tenorio le entregó en rehenes ${ }^{144}$, así como de las fortalezas de la merindad de Asturias tras la reducción del conde Alfonso de Noreña ${ }^{145}$.

\footnotetext{
133 García Luján, Libro de "Lo Salvado", p. 276.

134 Tejero Robledo, Arenas de San Pedro, p. 26.

135 Ibid. p. 30.

${ }^{136}$ Luis LóPez, "Villazgos señoriales", p. 189. Franco Silva, "La fiscalidad señorial”, p. 129.

137 1417, febrero, 15. MarTín, Mombeltrán, p. 140.

138 García Luján, Libro de "Lo Salvado", p. 219 y 275-277.

139 Ibid. p. 203.

140 García Luján, Libro de "Lo Salvado”, p.219 y 275-277; Argote de Molina, Nobleza de Andalucía, pp. 667-668 (según el reparto realizado por sus hijos en 1440)

141 García Luján, Libro de "Lo Salvado”, pp. 202-210.

142 Id.

143 AGS Mercedes y Privilegios, leg. 47, fol. 38; García Luján, Libro de "Lo Salvado", pp. 202-210; González Sánchez, La Corona de Castilla, pp. 329 y 1765.

${ }^{144}$ López de Ayala, Crónica de Enrique III, Año 1393, pp. 208-209.

${ }^{145}$ Ibid. Año, 1393, p. 232.
} 
También controló el castillo de Paredes de Navas, que tuvo en fialdad por orden de Enrique III, mientras se solucionaba la pugna por esta villa entre el conde de Noreña y don Pedro de Trastámara ${ }^{146}$. Por otro lado fue también tenente de las fortalezas de La Coruña, Betanzos y Vivero ${ }^{147}$, Ugéjar (Lorca), Carentín o Zahara de la Sierra, tras su conquista en $1407^{148}$. En el caso de los de Ugéjar y Carentín, sabemos que percibía 4.000 maravedíes anuales por la tenencia de ambos castillos ${ }^{149}$. Probablemente fue también alcaide las fortalezas portuguesas de Peñamacor y Miranda tras apoderarse de ellas en 1396 al romperse la tregua con Castilla ${ }^{150}$.

Asimismo, se beneficiaba de 3.000 maravedíes de renta que tenía en la cabeza de pecho de la aljama de los judíos de Segovia, hasta que en 1416 las cedió al monasterio de Santa María de Nieva, en compensación de los derechos que tenían a las casas que donó a los agustinos de Valladolid, a lo que le añadió en 1421, como ya hemos visto, 4.000 maravedís de renta anual en un juro que tenía en Carrión ${ }^{151}$.

A partir de la escueta información que nos da el hipotético reparto de sus bienes por sus herederos, sabemos que contaba con otras rentas, como los oficios de La Coruña, Betanzos y Vivero, o rentas en los pinares y la fuente de Villena, así como 3.000 maravedís de juro situados "en los libros del rey"152. Además, su mujer percibía otras rentas, como los 10.000 maravedís situados en la renta del pescado y de la carne de la ciudad de Toledo ${ }^{153}$.

Finalmente, dentro de la multitud de beneficios económicos que tuvo, sabemos que fue propietario de varias naves que empleaba en el comercio marítimo, como lo muestran las dos licencias que en 1409 el rey inglés, Enrique IV, le concedió para que pudieran comerciar con Inglaterra durante dos años, aunque pudo tener además otros buques ${ }^{154}$.

\footnotetext{
146 Ibid. Año 1394, p. 227.

147 Argote de Molina, Nobleza de Andalucía, pp. 667-668; Castrillo Llamas, La tenencia de fortalezas, p. 1227.

148 García de Santa María, Crónica de Juan II, p. 321.

149 AHNOB, Osuna, C. 286, D.27

150 González Dávila, Historia de la vida y hechos, p. 125; Castrillo Llamas, La tenencia de fortalezas, p. 1227.

151 Floranes "Noticias del convento de San Agustín", pp. 478-480.

152 Argote de Molina, Nobleza de Andalucía, pp. 667-668

153 AGS, Mercedes y privilegios, leg. 12, fol. 6; GonzÁlez SÁnchez, La Corona de Castilla, p. 2039.

154 González SÁnchez, La Corona de Castilla, pp. 2039-2040.
} 


\section{Cuadro 4}

Rentas y otros

\begin{tabular}{|l|l|}
\hline - Almona del jabón en Sevilla & - Almojarifazgo de Isdra \\
- 200.000 mrs. situados en las tahurerías de & - Almojarifazgo de Arjona \\
Sevilla & - Martiniega en la merindad de Castrojeriz \\
- Diezmo, alfolí y otros impuestos del & - Cabeza de pecho de la aljama de Segovia \\
condado de Ribadeo & - Tenencia de la fortaleza de Alcalá la Vieja \\
- Alcabalas de Ribadeo & -Tenencia de las fortalezas de la merindad de \\
- 8.500 mrs. en las alcabalas de Carrión. & Asturias \\
- Censos de Villena & - Tenencia de la fortaleza de La Coruña \\
- Tercias de Paredes de Nava & - Tenencia de la fortaleza Betanzos \\
- Tercias de Tordesillas y su arciprestazgo con & - Tenencia de la fortaleza Vivero \\
Velliza & - Tenencia del castillo de Paredes de Nava \\
- Tercias de Arjona & - Tenencia del castillo de Ugéjar (Lorca) \\
- Tercias de las localidades que tenía en Ávila & - Tenencia del castillo de Carentín \\
- Juro en Carrión & - Tenencia del castillo de Zahara de la Sierra \\
- Juro en Arjona & - Mantenimiento de 40 lanzas \\
- Juros situados en los libros del rey & - Oficios de La Coruña, Betanzos y Vivero \\
- Renta en los Pinares y en la Fuente de & - Alcaide de Peñamacor y Miranda \\
Villena & - Diferentes cantidades anuales para su \\
- Rentas de Lerín & mantenimiento \\
- Rentas de Dávalos & - licencia para comerciar con 2 naves en \\
& Inglaterra \\
\hline
\end{tabular}

\section{El reparto del patrimonio de Ruy López Dávalos}

La muerte de Enrique III en 1406 trajo como consecuencia un largo y complicado período de minoría, que se extendió hasta 1419, en la que durante la regencia del infante Fernando de Antequera y la reina Catalina de Lancaster, Ruy López Dávalos siguió teniendo un notable papel político, actuando como mano derecha de don Fernando. Fue a la muerte de éste y como consecuencia de las luchas por el poder que desencadenaron sus hijos, los infantes don Juan y don Enrique, cuando se produjo la caída del condestable. Su apoyo al infante don Enrique y su participación en 1420 en el denominado "golpe de estado de Tordesillas" y en los acontecimientos posteriores, supuso el final de su carrera política y su precipitada caída ${ }^{155}$. Así, tras la huida de Juan II junto con Álvaro de Luna desde Talavera a la Puebla de Montalbán, el condestable participó en el asedio al que el monarca fue sometido, lo que supuso su condena. Después del fracaso del sitio, Ruy López Dávalos, buscó refugio en Arjona, y aunque en enero de 1422 Juan II exigió que compareciera en la corte, se negó a ello, alegando encontrarse enfermo. Poco después, y coincidiendo con el apresamiento del infante don Enrique, huyó al reino de Valencia. Había sido acusado de traidor por tener tratos con el rey de

155 Sobre este episodio histórico vid. González SÁnchez, "Un "golpe de estado". 
Granada, a partir de una supuesta correspondencia con el monarca nazarí. En su huida, y bajo el amparo del rey de Aragón, se refugió en Valencia, donde permaneció hasta su muerte, el 6 de enero de 1428.

Tan pronto emprendió la huida, y antes incluso de que se iniciara el proceso contra él, Juan II ordenó que se le embargaran sus bienes. Envió a Jódar, donde se decía que guardaba un impresionante tesoro, a un criado de Álvaro de Luna, que encontró, como hemos visto, sólo 900 marcos de plata en vajilla. Paralelamente, se procedía al embargo de todo su patrimonio. Según nos relatan las Crónicas, a continuación se hicieron diez partes, que se repartieron entre el infante don Juan, que recibió dos, mientras que las ocho restantes se distribuyeron entre el arzobispo Sancho de Rojas; el almirante Alfonso Enríquez; el justicia mayor Pedro de Zúñiga; el adelantado Diego Gómez de Sandoval; Rodrigo Alonso Pimentel, conde de Benavente; Álvaro de Luna; Pedro de la Cerda y Fernán Alfonso de Robles ${ }^{156}$.

El 17 de junio de 1423 Juan II dictaba una sentencia que, considerando como había transcurrido el proceso, era más que predecible. En ella se establecía que don Ruy López Dávalos perdiera:

todos los bienes muebles e raíces e todas las villas e lugares e jurisdicciones e oficios e dignidades e tierras e lanzas e mercedes e raciones e quitaciones, y otros cualesquier bienes, actiones y derechos que el dicho Don Ruy López había e tenía e tiene e posee, velcassi e ser confiscados para la mi cámara e incorporado en mi fisco ${ }^{157}$.

El veredicto fue apelado sin ningún éxito, ya que el 30 de junio el monarca confirmaba el fallo ${ }^{158}$. Una vez pronunciada la sentencia no se esperó el año que estipulaban las leyes para hacerla efectiva, procediéndose casi inmediatamente a su ejecución. Así, poco después Juan II procedía a requisarle todos sus bienes, y sabemos que el 21 de julio de 1423 ordenó a su justicia mayor, Pedro de Zúñiga que secuestrase la villa de Arenas y la entregase al licenciado García Sánchez de Olmedo, para que la tuviera en nombre del rey ${ }^{159}$.

En septiembre de 1423 Juan II emitió una serie de documentos a través de los cuales efectuaba el reparto de los bienes del condestable. La partición que hizo varió de la que previamente se había establecido y, de hecho, Álvaro de Luna fue especialmente

\footnotetext{
${ }^{156}$ Galindez de Carvajal, Crónica de Juan II, p. 418 y p. 420; García de Santa María, Crónica de Juan II, p. 291. Dávalos y Ayala, Vida, hechos ilustres,155r.

157 1423, junio, 17. Valladolid. Guerrero Navarrete, Proceso y sentencia, p. 106.

${ }^{158}$ La apelación la presentó Fernando de Aranda, procurador de Ruy López Dávalos el 28 de junio de 1423. La sentencia definitiva se daba el 30 de junio. Guerrero NaVArrete, Proceso y sentencia, pp. 109121.

159 AHNOB, Osuna, C.1749, D.1.
} 
favorecido ${ }^{160}$. A través de la documentación conservada y de la información que nos ofrecen las Crónicas, podemos establecer a grandes rasgos cómo se efectuó el reparto, ya que hay algunas propiedades que no sabemos exactamente a quién correspondieron. Además, otros miembros de la corte que desconocemos se beneficiaron también, y parte de la hacienda del condestable revirtió en la Corona, como es el caso del condado de Ribadeo. Hemos sintetizado la repartición de los bienes del condestable en el cuadro 5, en el que se recogen los principales beneficiarios del reparto, aunque sabemos que los favorecidos fueron más, pertenecientes en su mayoría a la casa del rey ${ }^{161}$.

\section{Cuadro 5}

Reparto de los bienes confiscados al condestable. 1423

\begin{tabular}{|c|c|c|c|c|}
\hline Beneficiario & Señoríos & Oficios & $\begin{array}{l}\text { Propiedades } \\
\text { Inmobiliarias } \\
\end{array}$ & Rentas y otros \\
\hline Álvaro de Luna & $\begin{array}{l}\text { - La Adrada } \\
\text { - Castillo de } \\
\text { Bayuela }\end{array}$ & $\begin{array}{l}\text { - Condestable de } \\
\text { Castilla } \\
\text { - Camarero mayor } \\
\text { de la Cámara de los } \\
\text { paños }\end{array}$ & $\begin{array}{l}\text {-Bienes en San Martín } \\
\text { de Valdeiglesias } \\
\text { - Casas en La Adrada }\end{array}$ & $\begin{array}{l}\text { - } 39.000 \text { mrs. de las } \\
\text { rentas de las } \\
\text { jabonerías de Sevilla } \\
\text { - Rentas de Arjona }\end{array}$ \\
\hline $\begin{array}{l}\text { Infante don } \\
\text { Juan }\end{array}$ & $\begin{array}{l}\text { - El Colmenar } \\
\text { de las Ferrerías } \\
\text { (Mombeltrán) }\end{array}$ & & & \begin{tabular}{|l} 
- 5.000 mrs. de las \\
rentas de las \\
jabonerías de Sevilla \\
- 11.500 mrs. en \\
tributos de Arjona \\
- Las tercias de \\
Tordesillas y de \\
su arciprestazgo, \\
incluyendo Velliza \\
- Las tercias de \\
Paredes de Nava \\
- 8.500 mrs. en las \\
alcabalas de Carrión \\
- Censos de Villena \\
- 5.000 mrs. de \\
las martiniegas de \\
Castrojeriz \\
- 19.500 mrs. en las \\
alcabalas de Ribadeo
\end{tabular} \\
\hline $\begin{array}{l}\text { Pedro López de } \\
\text { Zúñiga }\end{array}$ & $\begin{array}{l}\text { - Candeleda } \\
\text { - Puebla de } \\
\text { Naciados } \\
\text { - Navia }\end{array}$ & $\begin{array}{l}\text { - Alcalde entre } \\
\text { moros y cristianos } \\
\text { del obispado de } \\
\text { Cartagena }\end{array}$ & $\begin{array}{l}\text {-Herrerías en Candeleda } \\
\text {-Heredades en La } \\
\text { Puebla de Alcocer }\end{array}$ & $\begin{array}{l}\text { - } 16.217 \text { mrs. situados } \\
\text { en las tahurerías de } \\
\text { Sevilla } \\
\text { - Tenencia de los } \\
\text { castillos de Ugejar y } \\
\text { Carentín } \\
\text { - } 6 \text { lanzas }\end{array}$ \\
\hline
\end{tabular}

$\overline{160}$ Acerca de la trayectoria vital de Álvaro de Luna es fundamental la obra de CALDERÓN ORTEGA, Álvaro de Luna.

161 García de Santa María, Crónica de Juan II, p. 321. 


\begin{tabular}{|c|c|c|c|c|}
\hline Beneficiario & Señoríos & Oficios & \begin{tabular}{|l|} 
Propiedades \\
Inmobiliarias \\
\end{tabular} & Rentas y otros \\
\hline $\begin{array}{l}\text { Rodrigo Alonso } \\
\text { Pimentel }\end{array}$ & $\begin{array}{l}\text { - Arenas de San } \\
\text { Pedro y sus aldeas }\end{array}$ & & $\begin{array}{l}\text { Herrerías, bodegas, } \\
\text { viñas y heredades en } \\
\text { términos de Arenas de } \\
\text { San Pedro }\end{array}$ & - Rentas de Arjona \\
\hline \begin{tabular}{|l|} 
Fadrique de \\
Castro, conde \\
de Trastámara
\end{tabular} & \begin{tabular}{|l} 
- Arjona \\
- Arjonilla \\
- La Higuera \\
- Recena \\
- Jimena \\
- Jódar \\
\end{tabular} & & & \\
\hline $\begin{array}{l}\text { Diego Gómez } \\
\text { de Sandoval, } \\
\text { conde de } \\
\text { Castro } \\
\end{array}$ & - Osorno & & & $\begin{array}{l}\text { - } 28.000 \text { mrs. de las } \\
\text { rentas de las jabonerías } \\
\text { de Sevilla }\end{array}$ \\
\hline \begin{tabular}{|l|} 
Alfonso \\
Enríquez
\end{tabular} & \begin{tabular}{|l} 
- Arcos de la \\
Frontera \\
- Torre de Lopera \\
- Torre de Gigonza
\end{tabular} & & & $\begin{array}{l}\text { - } 82.200 \text { mrs. de las } \\
\text { rentas de las jabonerías } \\
\text { de Sevilla } \\
-701 \text { mrs y } 5 \text { dineros } \\
\text { anuales de las rentas } \\
\text { de Arjona }\end{array}$ \\
\hline \begin{tabular}{|l|} 
Alonso Yáñez \\
Fajardo \\
\end{tabular} & & $\begin{array}{l}\text { - Adelantamiento de } \\
\text { Murcia }\end{array}$ & & \\
\hline $\begin{array}{l}\text { Fernán Alfonso } \\
\text { de Robles }\end{array}$ & & & & $\begin{array}{l}\text { - Diezmo y alfolí de } \\
\text { Ribadeo y Navia y } \\
\text { otros impuestos }\end{array}$ \\
\hline
\end{tabular}

Así pues, don Álvaro de Luna se benefició, además de la condestablía ${ }^{162}$ y del oficio de camarero mayor de la cámara de los paños ${ }^{163}$, de parte de los señoríos abulenses de López Dávalos, recibiendo las villas de la Adrada y Castillo de Bayuela ${ }^{164}$. Esta donación la completó con la entrega de todos los bienes que el antiguo condestable tenía en San Martín de Valdeiglesias ${ }^{165}$, y 39.000 maravedíes de la rentas de las jabonerías de Sevilla ${ }^{166}$, además de parte de las rentas de Arjona ${ }^{167}$.

Por su parte, el infante don Juan de Aragón, obtuvo la villa de El Colmenar de las Herrerías (actual Mombeltrán) ${ }^{168}$, junto con 5.000 maravedíes situados en las rentas

162 1423, septiembre, 10. Valladolid. RAH, Col. Salazar y Castro, M-5, fo 281v. y M-9, fo 272 a 274; Galíndez de Carvajal, Crónica de Juan II, p. 425. García de Santa María, Crónica de Juan II, p. 320. 163 1423, septiembre, 6. Valladolid. AHNOB, Osuna, C. 3315, D. 1.

164 1423, septiembre, 1. Cigales. AHPZ - P/001398/000019 El 4 de octubre de 1423 Juan de Gotor, alcaide de Escalona, tomó posesión de estas villas. RAH, Col. Salazar y Castro, M-9, fo 64v. El 27 de enero de 1424 Juan II confirmó esta donación. AHPZ - P/001398/000020

1651423 , octubre, 6. Valladolid. RAH, Col. Salazar y Castro, M-9, fo 63v. En 1434 Álvaro de Luna adquirió además la villa de San Martín de Valdeiglesias, perteneciente a la jurisdicción del monasterio allí situado. Franco Silva, "El destino del patrimonio", pp. 286-287.

166 1424, julio, 20, Segovia. AHNOB, Osuna, C. 496, D. 2.

167 VeGA, Cronología, fol. 303v.

168 García de Santa María, Crónica de Juan II, p. 320. Esta villa estuvo en manos del infante don Juan hasta 1429 se le confiscaron todos sus bienes pasando a formar parte esta villa al patrimonio del maestre 
de las jabonerías de Sevilla ${ }^{169} ; 11.580$ maravedíes en los fueros, derechos y tributos de Arjona y sus lugares ${ }^{170} ; 8.500$ maravedíes en las alcabalas de Carrión ${ }^{171}$; los censos de Villena ${ }^{172} ; 5.000$ maravedíes de moneda vieja en las martiniegas de la merindad de Castrojeriz ${ }^{173} ; 19.500$ maravedíes en las alcabalas de Ribadeo ${ }^{174}$; las tercias de Tordesillas y su arciprestazgo, incluyendo Velliza ${ }^{175}$ y las tercias de Paredes de Nava ${ }^{176}$.

Pedro López de Zúñiga recibió otra parte del señorío abulense, en el que se incluía la villa de Candeleda, con sus herrerías ${ }^{177}$ y la Puebla de Naciados ${ }^{178}$. Además el rey le entregó las heredades que tenía en La Puebla de Alcocer ${ }^{179} ; 16.217$ maravedíes de los situados en la tahurería de Sevilla; 14.573 maravedíes del mantenimiento asignado a don Ruy; la tenencia de los castillos de Ugéjar y Caretín, estimada en 4.000 maravedíes; 9.000 maravedíes para el mantenimiento de 6 lanzas; y la alcaldía entre cristianos y moros del obispado de Cartagena, valorada en 4.000 maravedíes ${ }^{180}$. También recibió el señorío de la puebla de Navia ${ }^{181}$.

El reparto de las tierras en Ávila se completó con la entrega a Rodrigo Alonso Pimentel, conde de Benavente, de las villas Arenas de San Pedro con sus aldeas El Arenal, El Hornillo, Guisando, Poyales del Hoyo, Hontanares, La Parra y Ramacastañas ${ }^{182}$. Además le concedió las herrerías, casas, bodegas y viñas que el condestable que tenía en término de Arenas ${ }^{183}$, asignándole también parte de las rentas de Arjona ${ }^{184}$.

de Calatrava, Luis González de Guzmán, hasta que en 1434, mediante una operación de trueque con el maestre, pasaría a poder de don Álvaro de Luna. Franco SiLVA, La fiscalidad señorial, pp. 129-131.

169 1423, septiembre, 1. Cigales. García Luján, Libro de "Lo Salvado", pp. 202-210. 1424, julio, 20, Segovia. AHNOB, Osuna, C. 496, D. 2.

170 1423, septiembre, 1. Cigales. García Luján, Libro de "Lo Salvado", pp. 202-210

171 Id.

$172 I d$.

173 Id.

174 Id.

175 García Luján, Libro de "Lo Salvado", pp. 275-277.

176 Según carta dada por Juan II el 1 de septiembre de 1423 en Cigales. García Luján, Libro de "Lo Salvado", pp. 202-210. Según se indica en esta carta, la suma de las tercias de Tordesillas y los censos de Villenas era de 50.500 maravedís.

177 García de Santa María, Crónica de Juan II, p. 320.

178 No nos ha legado el testimonio expreso del destino del señorío de La Puebla de Naciados, pero, considerando que poco después se encontraba entre los bienes de la casa de Los Zúñiga, es muy probable que Juan II se la donara a Pedro López de Zúñiga junto a Candeleda. Luss LóPEz, "Villazgos señoriales", p. 121.

179 1423, octubre, 6. Valladolid. AHNOB, Osuna, Cp. 100, D. 15.

180 1423, septiembre 6. Valladolid. AHNOB, Osuna, C. 286, D. 27.

181 Pedro de Zúñiga tomó posesión del señorío el 9 de enero de 1424. AHNOB, Osuna, C. 296, D.46.

182 1423, septiembre, 1. Cigales. AHNOB, Osuna, C.1749, D.1. García de Santa María, Crónica de Juan II, p. 320. El 7 de septiembre el conde de Benavente ordenó a su escudero, Luis Álvarez, que tomase posesión de la villa de Arenas. En 1432 pasó a los dominios de Álvaro de Luna como dote de su segunda esposa Juana Pimentel, hija del conde de Benavente. Franco SiLVA, "El destino del patrimonio", p. 285.

${ }_{183}$ AHNOB, Osuna, C.1749, D.1. El 7 de septiembre el conde de Benavente ordenó a su escudero, Luis Álvarez, que tomase posesión de la villa de Arenas.

184 VeGA, Cronología, fol. 303v. 
Por otro lado, el conde don Fadrique de Castro obtuvo los territorios que el condestable Dávalos había acumulado en el reino de Jaén. Así, a través de un privilegio fechado el 6 de septiembre de 1423, recibió los lugares de Jimena, Jódar y La Higuera ${ }^{185}$. Ese mismo día obtuvo el señorío de Arjona, con el título de duque, y Arjonilla, retrayendo el monarca de este señorío 11.580 maravedíes que debían de repartirse entre el condestable, el conde de Benavente y un tal Aguado ${ }^{186}$. Además, don Fadrique recibió los bienes que el condestable tenía en Mengíbar ${ }^{187}$.

Diego Gómez de Sandoval, adelantado mayor de Castilla, consiguió, además de la villa de Osorno ${ }^{188}$, 28.000 maravedíes situados en las rentas de las jabonerías de Sevilla ${ }^{189}$, mientras que el almirante Alfonso Enríquez recibió, además de la villa de Arcos de la Frontera y las torres de Lopera y Gigonza ${ }^{190}$, otra parte de las rentas de las jabonerías de Sevilla, valorada en 82.200 maravedíes, además de 701 maravedíes y 5 dineros anuales procedentes de las rentas de Arjona ${ }^{191}$.

El adelantamiento de Murcia lo obtuvo Alonso Yáñez Fajardo ${ }^{192}$, mientras que el contador mayor Fernán Alfonso de Robles, recibió las rentas que obtenía el condestable en el condado de Ribadeo ${ }^{193}$, aunque el control del señorío revirtió en la corona, hasta que en 1431 lo entregó Juan II a Rodrigo de Villandrando ${ }^{194}$.

Este reparto se realizó no solo sin esperar el año que la ley estipulaba, sino que tampoco se tuvo en cuenta que, a la par de la sentencia y condena del condestable, su mayordomo Álvaro Núñez de Herrera, pudo demostrar que las cartas presentadas por don Álvaro de Luna y que habían servido para acusarlo de tener tratos con el rey de Granada eran falsas, y que el autor de la falsificación había sido Juan García de Guadalajara, secretario de López Dávalos. Este, además de confesar, dio detalles de cómo se había realizado la falsificación ${ }^{195}$. En cualquier caso, la rehabilitación efectiva tardó en llegar, ya que ésta sólo se produjo a la muerte del condestable en 1428, por petición del infante don Enrique y del rey de Aragón, Alfonso V. Y aunque pudo rehabilitar su nombre ${ }^{196}$, no su capital,

185 1423, septiembre, 1. Cigales. Vega, Cronología, fol. 303v. García de Santa María, Crónica de Juan II, p. 320.

186 Idem.

187 ADMS. leg. 4990.

188 García de Santa María, Crónica de Juan II, p. 320.

189 1424, julio, 20, Segovia. AHNOB, Osuna, C. 496, D.2.

190 1423, agosto, 14. Tordesillas. AHNOB, Osuna, C. 496, D. 28. RAH, Col. Salazar y Castro, M-50, f. 202. García de Santa María, Crónica de Juan II, año 1423, p. 320.

191 1423, octubre, 1. Cigales. AHNOB, Osuna, C. 136, D. 52.

192 García de Santa María, Crónica de Juan II, p. 320.

193 RAH, Col. Salazar y Castro, M-62, fols. 52v-55v.

194 Paraje Méndez, El condado de Ribadeo, p. 448.

195 Dávalos y Ayala, Vida, hechos ilustres, fol. 157v. Galíndez de Carvajal, Crónica de Juan II, p. 419.

196 Dávalos y Ayala, Vida, hechos ilustres, fol. 176r. 
de lo cual se paresçe que mas por cobdiçia de sus bienes que por zelo de justiçia fue contra él procedido, graçias a la auariçia que en Castilla es entrada e la posee, lançando de ella vergueña e conçiençia, ca oy non tiene enemigos el que es malo, sinon el que es muy rico ${ }^{197}$.

Pese a las reclamaciones, sus hijos no pudieron hacer nada contra esta decisión y reparto. Posiblemente esperanzados en recuperar los bienes de su padre en 1440, según nos cuenta Argote de Molina, algunos de sus hijos se reunieron en Toledo para hacer un hipotético reparto de los bienes que habían pertenecido al condestable y que habían reclamado sin ningún éxito al rey Juan $\mathrm{II}^{198}$. Este queda reflejado en el cuadro $\mathrm{n}^{\mathrm{0}} 6$.

\section{Cuadro 6}

Reparto de bienes realizado por sus descendientes. 1440 , septiembre, 6 . Toledo

\begin{tabular}{|c|c|c|c|}
\hline Beneficiario & Señoríos & $\begin{array}{l}\text { Propiedades } \\
\text { inmobiliarias } \\
\end{array}$ & Rentas y otros \\
\hline $\begin{array}{l}\text { Pedro López } \\
\text { Dávalos }\end{array}$ & $\begin{array}{l}\text { - Arjona } \\
\text { - La Higuera } \\
\text { - Jimena } \\
\text { - Jódar } \\
\text { - Recena } \\
\text { - 1/2 Ibros } \\
\text { - Alharilla }\end{array}$ & $\begin{array}{l}\text { - Heredad de Alharilla } \\
\text { (Arjona) } \\
\text { - Casas y heredades en } \\
\text { Córdoba }\end{array}$ & \\
\hline $\begin{array}{l}\text { Diego López } \\
\text { Dávalos }\end{array}$ & $\begin{array}{l}\text { - Arenas } \\
\text { - El Colmenar } \\
\text { - La Adrada } \\
\text { - Castil de Bayuela } \\
\text { - Candeleda } \\
\text { - La Puebla del } \\
\text { Arañuelo } \\
\text { - Alija }\end{array}$ & - Heredad de Talavera & \\
\hline \begin{tabular}{|l|} 
Fernando \\
Dávalos
\end{tabular} & - Arcos de la Frontera & $\begin{array}{l}\text { - Aceñas de Guadalete } \\
\text { - Hacienda en Sevilla }\end{array}$ & $\begin{array}{l}\text { - Almona de jabón de } \\
\text { Sevilla }\end{array}$ \\
\hline Íñigo Dávalos & $\begin{array}{l}\text { - Ribadeo } \\
\text { - Navia }\end{array}$ & & $\begin{array}{l}\text { - Tenencia de la fortaleza } \\
\text { de La Coruña } \\
\text { - Oficios de La Coruña, } \\
\text { Betanzos y Vivero }\end{array}$ \\
\hline Alonso Dávalos & $\begin{array}{l}\text { - Osorno } \\
\text { - 1/2 Villabarva }\end{array}$ & - Hacienda en Carrión & $\begin{array}{l}\text { - Tercias de Paredes de } \\
\text { Nava }\end{array}$ \\
\hline
\end{tabular}

197 Pérez de Guzmán, Generaciones y semblanzas, pp. 27-28.

198 1440, septiembre, 6, Toledo. Documento redactado ante el escribano público Pedro Fernández del Azor. Argote de Molina, Nobleza de Andalucia, pp. 667-668. Lo recoge también Dávalos y Ayala, Vida, hechos ilustres, fol. 176v-177r. 


\begin{tabular}{|l|l|l|l|}
\hline Beneficiario & Señoríos & $\begin{array}{l}\text { Propiedades } \\
\text { inmobiliarias }\end{array}$ & Rentas y otros \\
\hline María Dávalos & $\begin{array}{l}\text { - Casas en Ávila } \\
\text { - Heredamiento en } \\
\text { Ávila }\end{array}$ & 2.000 florines \\
\hline $\begin{array}{l}\text { Hijos de Beltrán } \\
\text { Dávalos }\end{array}$ & & & $\begin{array}{l}3.000 \text { de juro situados en } \\
\text { los libros del rey }\end{array}$ \\
\hline Mencía Dávalos & & $\begin{array}{l}\text { 2.000 florines en } \\
\text { compensación por } \\
\text { Osorno, que le había dado } \\
\text { en dote por su matrimonio } \\
\text { con Gabriel Manrique }\end{array}$ \\
\hline $\begin{array}{l}\text { Constanza Tovar, } \\
\text { condesa de } \\
\text { Ribadeo (viuda } \\
\text { del condestable) }\end{array}$ & & $\begin{array}{l}\text { - La heredad de } \\
\text { Madrigal } \\
\text { - La heredad de } \\
\text { Alharaz }\end{array}$ & $\begin{array}{l}\text { los Pinares y en la Fuente } \\
\text { de Villena } \\
-10.000 \text { maravedíes de } \\
\text { juro en compensación de } \\
\text { la villa de Alharilla }\end{array}$ \\
\hline
\end{tabular}

Es interesante destacar que este convenio se efectuó una fecha clave de la política castellana, ya que coincide en el tiempo con la caída de don Álvaro de Luna ${ }^{199}$ tras el levantamiento de parte de la nobleza y el regreso a Castilla de los infantes de Aragón. Precisamente en ese momento se estaban desarrollando las Cortes en Valladolid en las que los infantes redactaron un manifiesto en el que se recogieron numerosos agravios contra don Álvaro ${ }^{200}$. Es posible que, en esta victoria de los infantes, los descendientes de don Ruy vieran alguna esperanza de recuperar el patrimonio de su padre y de ahí que se reunieran para realizar su hipotética distribución.

A la hora de analizar este reparto, hay que destacar la desigualdad de los bienes recibidos por cada una de las partes, siendo los más beneficiados los dos hijos mayores del condestable, Pedro y Diego, que se repartieron la mayor parte de sus propiedades. En la partición se incluyeron los hijos de Beltrán Dávalos, que había fallecido. Sin embargo, no participó doña Leonor, ya que ésta había renunciado a la parte de la herencia que le correspondía en favor de su hermano Diego ${ }^{201}$, quien por eso posiblemente obtuvo un lote mayor. Tampoco figura Constanza Dávalos, a quien Juan Dávalos consigna como hija del condestable y de su segunda esposa, Elvira de Guevara, ni Rodrigo Dávalos, quien según el mismo autor era hijo de Constanza de Tovar, su tercer matrimonio ${ }^{202}$. Es, por otro lado, interesante que en la parte de Pedro López Dávalos se incluyera

\footnotetext{
${ }_{199}$ El 22 de octubre de 1439 se firmó el acuerdo de Castronuño que imponía el destierro de don Álvaro de Luna y la restitución de la situación económica de los infantes Juan y Enrique a la situación económica anterior a 1425. SuÁrez Fernández, "Los Trastámaras de Castilla y Aragón", p. 158.

${ }^{200}$ Olivera Serrano, "Las Cortes de Castilla", p. 249.

201 S.f. AHNOB, Frías, C.839, D.3.

${ }^{202}$ Dávalos y Ayala, Vida, hechos ilustres, fol. 233r.
} 
también el señorío de Ibros que el condestable Dávalos había entregado como dote a su hija Leonor cuando se casó con Men Rodríguez II de Benavides ${ }^{203}$. Desconocemos las razones de esto, teniendo en cuenta además que en esas fechas doña Leonor controlaba el señorío de Ibros sin ningún problema y se mantuvo en manos de sus descendientes a su muerte en $1469^{204}$. Algo distinto ocurre con Mencía Dávalos, que había recibido en dote la villa de Osorno cuando contrajo matrimonio con Gabriel Manrique, comendador mayor de Castilla en la Orden de Santiago ${ }^{205}$. Sin embargo, tras la confiscación de los bienes del condestable en 1423, Juan II la donó a Diego Gómez de Sandoval, conde de Castro, por lo que pasó a formar parte del condado de Castro, que le concedió el monarca en $1426^{206}$. En este caso, los descendientes de don Ruy López Dávalos, al considerar posiblemente que no podían recuperar Osorno compensaban a doña Mencía con 2.000 florines. Gabriel Manrique, marido de doña Mencía, había iniciado un contencioso contra el conde de Castro, alegando que esta villa pertenecía a su mujer, que ganó finalmente, consiguiendo la propiedad de esta villa con el título de condado por concesión de Juan II en $1445^{207}$.

En cualquier caso, el documento era un mero desiderátum que nunca se pudo llevar a término.

\section{Conclusiones}

A través de estas páginas hemos podido ver cómo el progreso político de Ruy López Dávalos, propició su ascenso social y económico, convirtiéndose de este modo en el prototipo de una nobleza de promoción gracias al servicio de la Corona. En el caso concreto del condestable, podemos comprobar que partiendo prácticamente desde cero consiguió acumular a lo largo de su vida una fortuna bastante notable. Parte procedió de la profusa cantidad de cargos y títulos para los que fue nombrado, entre los que destaca el de condestable. No siempre los ejerció directamente, pero le reportaron importantes beneficios económicos. Junto a ello, se vio beneficiado con un estado señorial nada desdeñable, localizado principalmente en los obispados de Ávila y Jaén, así como con abundantes rentas. Gracias a los cuantiosos beneficios económicos que este patrimonio le reportó consiguió incrementarlo mediante algunas compras.

\footnotetext{
${ }^{203}$ Esta pequeña localidad estaba dividida en dos jurisdicciones, una perteneciente al concejo de Baeza, la otra estaba señorializada desde el siglo XIV. CArmona Ruiz, "Nuevos datos", p. 136.

204 Carmona Ruiz, "Nuevos datos”, pp. 138-139.

205 Rodicio García, “El señoríos y condado de Osorno”, p. 345.

206 Franco Silva, "El linaje Sandoval", p. 51.

${ }^{207}$ Lopez de Haro, Nobiliario, tomo I, pp. 320-322. El matrimonio de Gabriel Manrique y Mencía Dávalos fue anulado por parentesco (doña Mencía se había tomado esponsales con Juan Manrique, II conde de Castañeda, aunque ese matrimonio no llegó a consumarse), por lo que en 1451 Mencía López Dávalos ingresó en el monasterio de Amusco, que posteriormente se trasladaría al de Calabazanos. SALAZAR Y CAstro, Historia genealógica, tomo I, p. 609.
} 
Su apoyo al infante don Enrique, que se plasmó en su participación directa en el denominado "Golpe de estado Tordesillas" de 1420 y la aparición en la corte de Juan II de un intrigante y ambicioso personaje, Álvaro de Luna, constituyeron la combinación perfecta para propiciar la caída del condestable, que fácilmente pudo ser derrotado al haberse incorporado muy recientemente a la oligarquía y por lo tanto no había conseguido crear una red de alianzas lo suficientemente potente para poder contrarrestar los ataques que sufrió. Aunque se puede considerar que fue Álvaro de Luna el que propició la caída del condestable, esta no pudo haberse producido tan fácilmente sin la connivencia de otros nobles, que en algún momento se pudieron sentir menoscabados, y que se vieron también beneficiados de su caída política y del reparto de su patrimonio. La desaparición de la escena política de Ruy López Dávalos supuso además que parte de sus descendientes fueran apartados también del poder, que económicamente se vieran perjudicados y que sus intentos por recuperar el patrimonio paterno fueran en vano. Sólo los hijos que siguieron al servicio del infante don Enrique, y los que acompañaron al condestable en su exilio a Valencia, consiguieron mantener cierto estatus, al pasar a formar parte estos últimos de la corte real de Alfonso V, y participar muy activamente en la política mediterránea del monarca aragonés.

\section{Bibliografía citada}

Argote de Molina, Gonzalo, Nobleza de Andalucía. Jaén, Ed. Riquelme y Vargas, 1991. Ariz, Luis, Historia de las grandezas de la ciudad de Ávila, Alcalá de Henares, 1607. BaEna, Juan Alfonso de, El Cancionero de Juan Alfonso de Baena (siglo XV), Madrid, Imp. Rivadeneyra, 1851.

BARRIENTos, Lope, Refundición de la Crónica del halconero, por el obispo Don Lope Barrientos, (hasta ahora inédita). Ed. Juan de Mata Carriazo, Madrid, Espasa-Calpe, 1946.

BARrios, Ángel; Luis, Fernando; Riaño, Eugenio, Documentación Medieval del Archivo Municipal de Mombeltrán, Ávila, Institución "Gran Duque de Alba”, 1996.

Bermúdez Aznar, Agustín. El corregidor en Castilla durante la Baja Edad Media (1348-1474). Universidad de Murcia, 1974.

Calderón Ortega, José Manuel, Álvaro de Luna: riqueza y poder en la Castilla del siglo XV, Madrid, 1998.

CaÑas Gálvez, Francisco de Paula. "La Casa de Juan I de Castilla: aspectos domésticos y ámbitos privados de la realeza castellana a finales del siglo XIV (ca. 1370-1390)". En la España medieval, 34, 2011, pp. 133-180.

Carmona Ruiz, María Antonia (2014), "Nuevos datos sobre el proceso de señorialización de Andalucía: la evolución del señorío Ibros (Jaén) entre los siglos XIV y XV". Historia y Genealogía, 2014, 4, pp. 133-150. 
Carmona Ruiz, María Antonia, "Los avatares de un señorío de frontera en la Baja Edad Media. Jódar (Jaén) entre los siglos XIII y XV”, En la España Medieval, 2017, 40, pp. 163-189.

Carrillo de Huete, Pedro, Crónica del halconero de Juan II. Ed. Juan de Mata Carriazo. Sevilla, Universidad, 2006.

Carvajal de la Vega, David, "Crédito privado en Castilla a fines del siglo XV. Una introducción a su estudio". Anuario de estudios medievales, 47-1, 2017, pp. 3-36.

Cascales, Francisco, Discursos históricos de Murcia y su reino, Murcia, 1621.

Castrillo Llamas, Concepción, La tenencia de fortalezas en la Corona de Castilla durante la Baja Edad Media: (relaciones de poder entre monarquía, nobleza y ciudades) Siglos XIII-XV. Tesis Doctoral, Madrid, Universidad Complutense, 1997.

Castro, José Ramón, Archivo General de Navarra. Catálogo de la Sección de Comptos. Documentos. Tomos 20 al 35, Pamplona, 1957-1964.

Снамосно Cantudo, Miguel Ángel, Justicia real y justicia municipal: la implantación de la justicia real en las ciudades giennenses (1234-1505), Jaén, Universidad, 1998.

Collantes de Terán SÁnchez, Antonio, "Un pleito sobre bienes de conversos sevillanos en 1396”. Historia. Instituciones. Documentos, 1976, 3, pp. 169-185.

Crónica anónima de Enrique III de Castilla (1390-1391) (ed. Michel Garcia), Madrid, Marcial Pons, 2013.

DÁvalos de Ayala, Juan, Vida, hechos ilustres y sucesión gloriosa de don Ruy López Dáualos el Bueno, tercer condestable de Castilla, conde de Ribadeo, adelantado mayor del reyno de Murcia. (ed. María Antonia Carmona), Jaén, Instituto de Estudios Giennenses, 2021.

Delgado Merchán, Luis, Historia documentada de Ciudad Real (la judería, la Inquisición y la Santa Hermandad), Ciudad Real, 1907.

DíAz de GAmes, El Victorial, ed. de R. Beltrán Llavador, Salamanca, Universidad, 1997.

FlorAnes, Rafael, "Noticias del convento de San Agustín de Valladolid", CODOIN, 1852, pp. 476-502.

ForondA, François, "La privanza dans la Castille du bas Moyen Âge. Cadres conceptuels et stratégies de légitimation d'un lien de proximité”, Cahiers d'Études Hispaniques Médiévales, 2004,16, pp. 153-197.

Franco SiLVA, Alfonso, "El linaje Sandoval y el señorío de Lerma en el siglo XV", Anales de la Universidad de Cádiz, 1, 1984, pp. 45-61.

Franco Silva, Alfonso, "El destino del patrimonio de don Álvaro de Luna. Problemas y conflictos en la Castilla del siglo XV", La fortuna y el poder. Estudios sobre las bases económicas de la aristocracia castellana (s. XIV-XV), Cádiz, 1996, pp. 549-584.

Franco Silva, Alfonso, "La fiscalidad señorial en el Valle del tiétar: el ejemplo de Mombeltrán”, Anuario de Estudios Medievales, 34/1, 2004, pp. 125-216. 
Galíndez de Carvajal, Lorenzo, Crónica de Juan II. Ed. Cayetano Rosel, BAE, 1877. García de Santa María, Alvar, Crónica del reinado de Juan II, CODOIN, vol. XCIX, Madrid, 1891.

García Luján, José Antonio, Libro de "Lo Salvado" de Juan II de Castilla, Córdoba, Universidad, 2001.

GonzÁlez, Tomás, Colección de privilegios, franquezas, exenciones y fueros concedidos á varios pueblos y corporaciones de la Corona de Castilla, Madrid, 1830.

González Dávila, Gonzalo, Historia de la vida y hechos del rey don Henrique III, Madrid, 1638.

GonzÁlez Moreno, Joaquín, Las reales almonas de Sevilla, Sevilla, 1975.

GonzÁlez SÁnchez, Santiago, La Corona de Castilla: Vida política (1406-1420), acontecimientos, tendencias y estructuras. Tesis doctoral, Madrid, Universidad Complutense, 2010.

GonzÁlez SÁnchez, Santiago, Las relaciones exteriores de Castilla comienzos del siglo XV. La minoría de Juan II (1407-1420), Madrid, Comité Español de Ciencias Históricas, 2013.

GonzÁlez SÁnchez, Santiago, "Un "golpe de estado" y sus consecuencias: el gobierno del infante don Enrique en Castilla (julio-diciembre de 1420)" En la España medieval, 36, 2013, pp. 155-181.

González SÁnchez, Santiago, La alta nobleza castellana a comienzos del siglo XV. Consolidación de linajes y casas nobles, Madrid, Comité Español de Ciencias Históricas, 2018.

Guerrero Navarrete, Yolanda, Proceso y sentencia contra Ruy López Dávalos, condestable de Castilla, Jaén, Instituto de Estudios Giennenses, 1982.

López de Ayala, Pedro. Crónica de Juan I. Ed. Cayetano Rosel, BAE, 1877.

LóPez de Ayala, Pedro. Crónica de Enrique III. Ed. Cayetano Rosel, BAE, 1877.

LóPez de HARo, Alonso. Nobiliario genealógico de los reyes y títulos de España. Madrid, 1622.

Luis López, Carmelo. Documentación Medieval de los Archivos Municipales de La Adrada, Candeleda, Higuera de las Dueñas y Sotillo de la Adrada. Ávila, Institución Gran Duque de Alba, 1992.

LUIS LóPEZ, Carmelo. "Villazgos señoriales en el sector meridional del alfoz a finales del siglo XIV" en G. del Ser Quijano (coord) Historia de Ávila, IV, Ávila, Institución Gran Duque de Alba, 2009, pp. 111-260.

Luis LóPEz, Carmelo y Ser Quijano, Gregorio del, Documentación medieval del Asocio de la Extinguida Universidad y Tierra de Ávila, vol. I, Ávila, 1990.

MarianA, Juan de, Historia general de España, Toledo, 1601. 
Martín García, Gonzalo, Mombeltrán en su Historia (siglo XIII-siglo XIX), Ávila, Institución Gran Duque de Alba, 1997.

Martín GutiérRez, Emilio, 2003. La identidad rural de Jerez de la Frontera. Territorio y poblamiento durante la Baja Edad Media, Cádiz, Universidad, 2003.

Martínez CARrillo, María de los Llanos, Revolución urbana y autoridad monárquica en Murcia durante la Baja Edad Media (1395-1420), Murcia, 1980.

Martz, Linda. A Network of Converso Families in Early Modern Toledo. Assimilating a Minority. Michigan, The University of Michigan Press, 2003.

Mitre Fernández, Emilio, Evolución de la nobleza en Castilla bajo Enrique III (13691406). Valladolid, Universidad, 1968.

Mitre Fernández, Emilio, La extensión del régimen de corregidores en el reinado de Enrique III de Castilla, Valladolid, Universidad, 1969.

Mitre Fernández, Emilio, "Mecanismos institucionales y poder real en la Castilla de Enrique III”. En la España medieval, 1980, 1, pp. 317-328.

Mitre Fernández, Emilio, Los judios de Castilla en tiempo de Enrique III. El pogrom de 1391, Valladolid, Universidad, 1994.

Molina Hipólito, José, Guía de Úbeda, Madrid, Dirección General de Bellas Artes, 1965.

Molina Rozalem, Juan Francisco, "Una fortaleza en la frontera occidental castellanonazarí: la torre de Lopera", Segundas Jornadas sobre Historia, arquitectura y construcción fortificada. Madrid, 2016.

Montes Romero-Camacho, Isabel, "Antisemitismo sevillano en la Baja Edad Media: el pogrom de 1391 y sus consecuencias". La sociedad medieval andaluza, grupos no privilegiados. Actas del III Coloquio de Historia Medieval Andaluza, Jaén, Diputación, 1984, pp. 57-75.

Montes Romero-CAmacho, Isabel, "La polémica del testamento de Juan I de Castilla y sus implicaciones sevillanas". Historia. Instituciones. Documentos, 1998, 25, pp. 468-472.

Montes Romero-CAMACHO, Isabel, "El converso sevillano Nicolás Martínez de Medina (o de Sevilla), contador mayor de Castilla. Apuntes para una biografía", Espacio, Tiempo y Forma, Serie III, H. ${ }^{a}$ Medieval, 2014, 27, pp. 343-380.

MuÑoz Gómez, Víctor, "La adquisición de dominios señoriales en la Castilla bajomedieval. Fernando de Antequera y Paredes de Nava (1380-1408)". Actas III simposio Internacional de Jóvenes Medievalistas, Lorca, 2006, pp. 121-132.

MuÑoz Gómez, Víctor, El poder señorial de Fernando "el de Antequera” y los de su “casa”. Señorio, redes clientelares y sociedad feudal en Castilla durante la Baja Edad Media, Madrid, CSIC, 2018.

Narbona, Eugenio, Historia de D. Pedro Tenorio, arçobispo de Toledo, Toledo, 1624.

Nogales Rincón, David, "Un año en la corte de Enrique III de Castilla (1397-1398)". En la España Medieval, 2014, vol. 37 85-130. 
Olivera Serrano, César, "Las Cortes de Castilla y el poder real (1431-1444)", En la España medieval, 11, 1988, pp. 223-260.

PARAJe MÉndez, Alberto, "El Condado de Ribadeo en la reorganización del orden nobiliario trastamarista de Galicia”, Nalgures, XII, 2016, pp. 427-450.

Perea Rodríguez, Óscar, "El Cancionero de Baena como fuente historiográfica de la Baja Edad Media castellana: el ejemplo de Ruy López Dávalos", Cancioneros en Baena: actas del II Congreso Internacional "Cancionero de Baena”. "In memoriam” Manuel Alvar, vol. I, Baena, 2003, pp. 293-333.

PÉRez Bustamante, Rogelio, El gobierno y la administración territorial de Castilla, I, Madrid, Universidad Autónoma, 1976.

PÉrez de GuZmán, Fernán, Generaciones y semblanzas, Madrid, Austral, 1947.

Porras Arboledas, Pedro Andrés, "La aristocracia urbana de Jaén bajo los Trastámara: los Mendoza y los Berrio”, En La España Medieval, 1990, 13, pp. 271-302.

Quesada Quesada, Tomás. La serranía de Mágina en la baja edad media: (una tierra fronteriza con el reino nazarí de Granada), Granada, Universidad, 1989.

Reviejo Paz, José Adolfo. La casa de Villafranca de la Sierra y Las Navas durante la Edad Media. Tesis doctoral, UNED, 2018.

Rico CAllado, Francisco Luis, "Los censos consignativos en Castilla, siglos XV-XVI. Una aproximación a su implantación a través de la práctica notarial", Tiempos ModerNOS, 41, 2020, PP. 34-55.

Rodicio García, Sara, “Osorno y su condado. El señorío y condado de Osorno”. Publicaciones de la Institución Tello Téllez de Meneses, 62, 1991, pp. 337-484.

Rojas Gabriel, Manuel, "La señorialización de una marca fronteriza: Arcos, Medina Sidonia y Alcalá de los Gazules a mediados del siglo XV", Estudios sobre Málaga y el Reino de Granada en el V Centenario de la Conquista, Málaga, Diputación, 1987, pp. 131-152.

RuAno y Prieto, Francisco, "El condestable d. Ruy López Dávalos, primer duque de Arjona". Revista de archivos, bibliotecas y museos, 1903, tomos VIII (pp. 167-181), IX (pp. 166-177) y 1904, tomo XI (pp. 398-408).

Rubio Martínez, Amparo, "La Hacienda Real en Galicia en tiempos de Juan II (14061454)", En la España Medieval, 2008, vol. 31, pp. 413-474.

Salazar y Acha, Jaime, La Casa del Rey de Castilla y León en la Edad Media, Madrid, Centro de Estudios Políticos y Constitucionales, 2000.

SAlazAr y ACHA, Jaime, "La nobleza titulada medieval en la Corona de Castilla", Anales de la Real Academia Matritense de Heráldica y Genealogía, 2008, 11, pp. 7-94.

Salazar y CAstro, Luis de, Historia genealógica de la Casa de Lara, Madrid, 1696.

SuÁrez FernÁndeZ, Luis, "Los Trastámaras de Castilla y Aragón en el siglo XV (140774)", Historia de España Menéndez Pidal, tomo XV, Madrid, 1993, pp. 3-322. 
SuÁrez Fernández, Luis, "Auge y caída de un hombre nuevo: el condestable Ruy López Dávalos". Boletín de la Real Academia de la Historia, Tomo 195, Cuaderno 1, 1998, pp. 43-80.

Tejero Robledo, Eduardo. Arenas de San Pedro. Andalucía de Gredos, Madrid, 1975. Tejero Robledo, Eduardo (2000) "Emergencia del Valle del Tiétar a fines del siglo XIV: Política de Ruy López Dávalos en sus cartas de villazgo" en J.A. ChavarRía Vargas, J.M. GonzÁlez MuÑoz, E. Tejero Robledo, Villas y villazgos en el valle del Tiétar abulense (siglos XIV-XVIII), Madrid, Sociedad de Estudios del Valle del Tietar (SEVAT), 2000, pp. 9-35.

Torres Fontes, Juan, "El Alcalde entre moros y cristianos del reino de Murcia", Hispania: Revista española de Historia, 78, 1960, pp. 55-80.

Torres Fontes, Juan, "Los condestables de Castilla en la Edad Media". Anuario de Historia del Derecho Español, 1971, 41, pp. 57-112.

VegA, fray Malaquías de la, Cronología de los Ilmos. Jueces de Castilla Nuño Nuñez Rasura y Layn Calvo... BNE, MSS/19418.

Vilaplana Montes, Ma Asunción, "Un ajuste de cuentas del alcabalero mayor de Sevilla Pedro Ortiz (1420)". Historia. Instituciones. Documentos, 1, 1974, pp. 417-501.

Ximena JuRAdo, Martín de, Historia, o Anales del municipio albense urgavonense, o villa de Arjona. Edición y estudio preliminar Rafael Frías Martín, Arjona, Ayuntamiento, 1996. ZuRITA, Jerónimo, Anales de Aragón. Edición de Ángel Canellas López. Ed. electrónica de José Javier Iso, María Isabel Yagüe y Pilar Rivero. http://ifc.dpz.es/recursos/ publicaciones/24/48/ebook2473.pdf. 